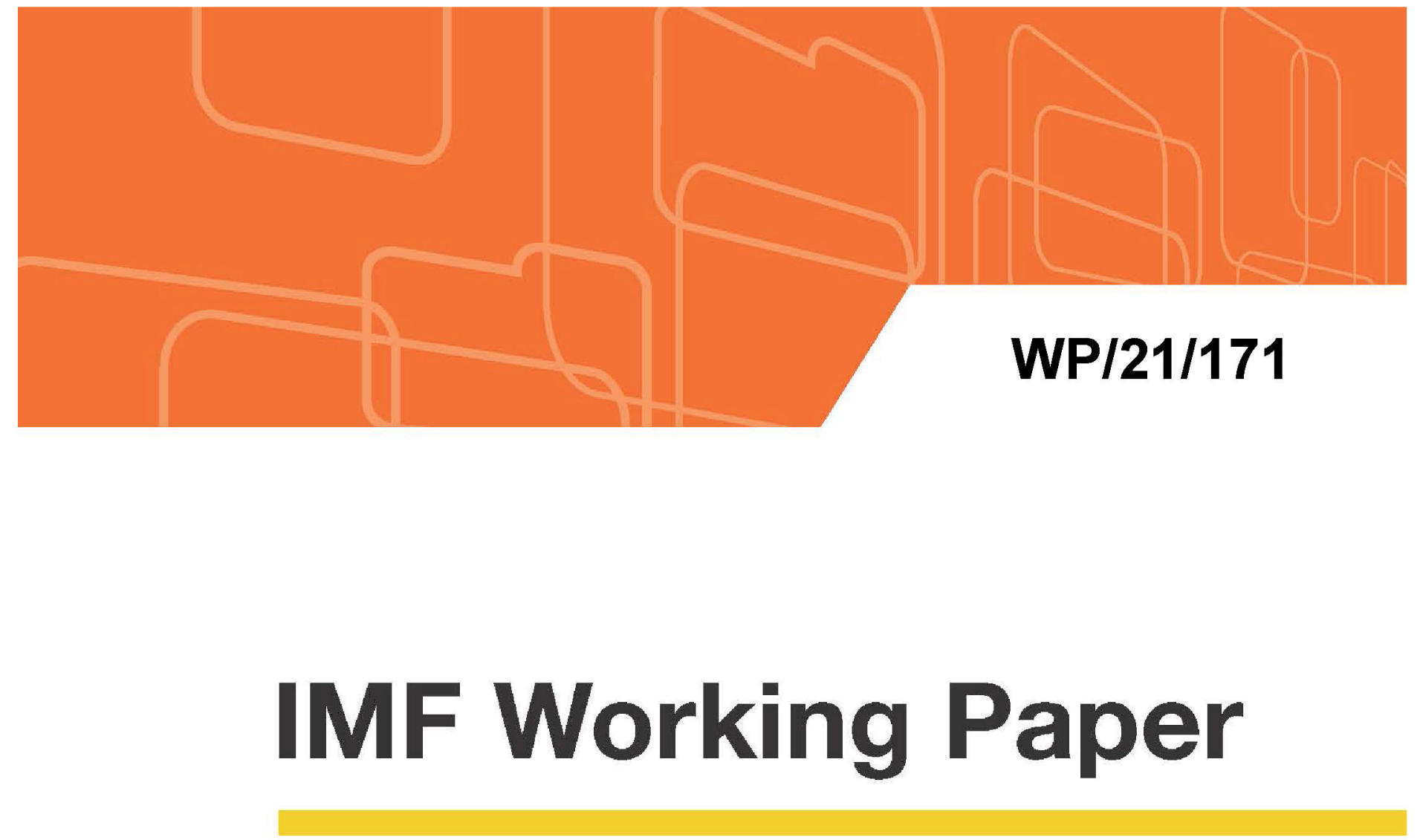

\title{
Fiscal Policies for Achieving Finland's Emissions Neutrality Target
}

by lan Parry and Philippe Wingender

IMF Working Papers describe research in progress by the author(s) and are published to elicit comments and to encourage debate. The views expressed in IMF Working Papers are those of the author(s) and do not necessarily represent the views of the IMF, its Executive Board, or IMF management. 


\title{
IMF Working Paper
}

European Department

\section{Fiscal Policies for Achieving Finland's Emission Neutrality Target \\ Prepared by Ian Parry and Philippe Wingender ${ }^{1}$}

Authorized for distribution by Peter Dohlman

June 2021

\section{IMF Working Papers describe research in progress by the author(s) and are published to elicit comments and to encourage debate. The views expressed in IMF Working Papers are those of the author(s) and do not necessarily represent the views of the IMF, its Executive Board, or IMF management.}

\begin{abstract}
Finland has pledged to cut net greenhouse gas emissions to zero by 2035 and has sectoral targets for deploying electric vehicles, phasing out coal generation, and oil-based space heating. Fiscal policies at the national and sectoral level could play a critical role in achieving these objectives. Carbon dioxide emissions are already priced significantly in Finland but prices vary substantially across fuels and sectors. The paper discusses a reform to both scale up, and progressively harmonize, pricing while using revenues to address equity issues. It also discusses the potential use of revenue-neutral feebate schemes to strengthen mitigation incentives for the transportation, industry, building, forestry, and agricultural sectors.
\end{abstract}

JEL Classification Numbers: Q48, Q54, Q58, H23

Keywords: Climate change, Finland climate mitigation, carbon pricing, feebate, revenue recycling, border carbon adjustment, transportation, forestry.

Author's E-Mail Address: iparry@,imf.org; pwingender@imf.org.

\footnotetext{
${ }^{1}$ With contributions from Raju Huidrom. The authors are grateful to Veli Auvinen, Peter Dohlman, Raju Huidrom, Jussi Kiviluoto Jenni Oksanen and Ilari Valjus for very helpful comments on an earlier draft. All errors remain our own.
} 
Abstract

I. Introduction

II. Background on Emissions Trends and Policies

III. Fiscal Incentives for Progressing on National and Sectoral Targets for Fossil Fuel Emissions .

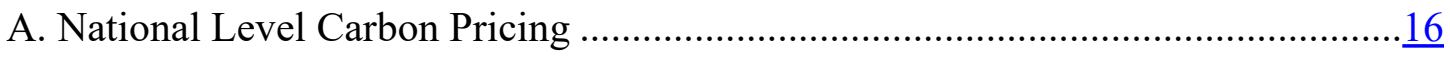

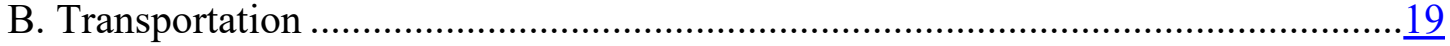

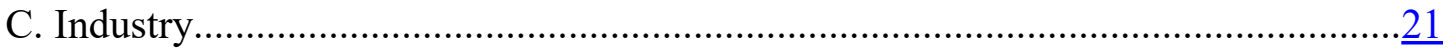

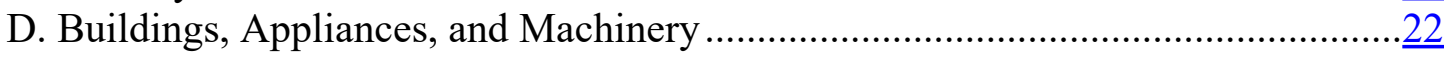

IV. Addressing the Burden of Carbon Pricing on Households and Firms ............................22

A. Promoting Equitable Pricing Reform........................................................

B. Carbon Pricing, Leakage, and Competitiveness..................................................29

V. Mitigation Policies for Forestry and Agriculture ................................................... $\frac{31}{31}$

A. Promoting Carbon Storage from Forestry and Land Use Changes....................... 31

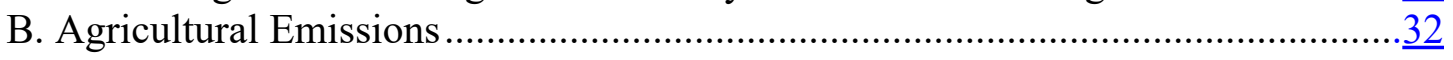

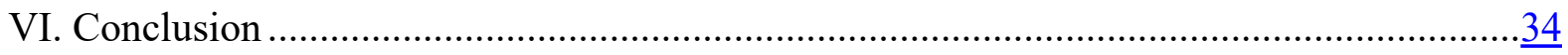

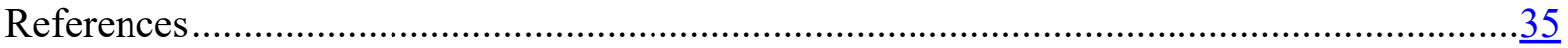

\section{Tables}

1. Recommended Package of Fiscal Instruments to Reinforce Finland's Climate Mitigation

Strategy

2. Comparing Emission Reduction Targets from EU and National Pledges ........................... $\frac{8}{8}$

3. Effective Carbon Prices by Major Fuel Type in Finland, €/tonne 2020 .........................12

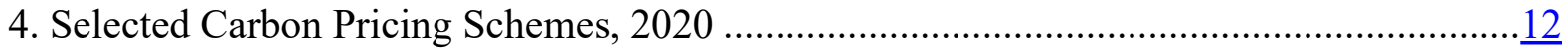

5. Key Design Issues for BCAs: A Summary ............................................................ $\frac{30}{34}$

6. Impact of a $€ 20$ Per Tonne of $\mathrm{CO}_{2}$ Equivalent Feebate on Agriculture ............................ 34

\section{Figures}

1. Global Fossil Fuel $\mathrm{CO}_{2}$ Emissions....

2. Trends in Fossil Fuel $\mathrm{CO}_{2}$ Emissions ......................................................................

3. GHG Emissions and LULUCF Withdrawals in Finland .............................................

4. Breakdown of GHG Emissions, 2018 .......................................................................

5. Historical EU ETS Allowance Prices ......................................................................

6. Supply Cost, Environmental Cost, and Fuel Product and Country, 2017 ........................14

7. Registration Tax Schedule by $\mathrm{CO}_{2}$, Emission Rate (Percent) .........................................15

8. Basic Vehicle Tax Schedule by $\mathrm{CO}_{2}$, Emission Rate $(€ /$ year)........................................15

9. Reduction in Fossil Fuel $\mathrm{CO}_{2}$ From Emission Target and Carbon Pricing in 2030, Selected

Countries..... 
10. $\mathrm{CO}_{2}$-Based Components of Vehicle Taxes, Selected Countries....................................20

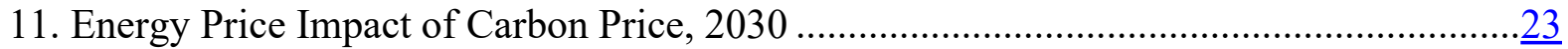

12. Household Energy Consumption, By Source ............................................................ 24

13. Energy Consumption Share by Source ....................................................................25

14. Carbon Tax Burden by Source ............................................................................. $\frac{26}{27}$

15. Marginal Tax Rate Schedules for Labor Income ....................................................27

16. Incidence of Higher Carbon Pricing and Reform Options.............................................28

17. Carbon Leakage Rate of National Policies ...............................................................29

18. Illustrative Impact of a Feebate on Agriculture ......................................................

\section{Appendices}

I. Burden of Carbon Mitigation Policies on Industries ................................................. $\frac{39}{41}$

II. Household Incidence of a Carbon Tax ................................................................... $\frac{41}{45}$

III. Design Issues for a BCA: Further Discussion ...................................................... $\frac{45}{47}$

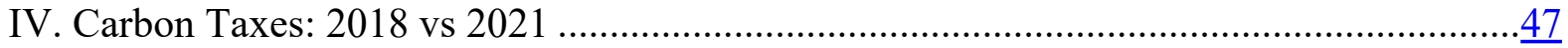




\section{INTRODUCTION}

Finland has cut greenhouse gas (GHG) emissions by about a fifth since 1990 and has set a highly ambitious goal of becoming emissions neutral-meaning annual carbon dioxide $\left(\mathrm{CO}_{2}\right)$ equivalent emissions must be offset by annual absorption from carbon sinks - by 2035. To support this goal, Finland also has sectoral targets, for example, for deploying electric vehicles (EVs) and phasing out coal generation and oil-based heating for buildings.

Although carbon emissions in Finland are already subject to significant pricingindeed Finland was the first country to introduce a carbon tax in 1990 - the government and others recognize that further measures are needed to achieve Finland's emissions neutrality by $\mathbf{2 0 3 5}$. Reflecting this, the Finnish government is preparing additional energy pricing and sectoral measures to help bridge the gap. In this context, this paper proposes a package of fiscal measures that scales up and harmonizes carbon pricing and combines it with revenue-neutral feebates (tax-subsidy schemes) to reduce emissions per unit of production or activity in the transport, industrial, building, forestry and agricultural sectors (power will be largely decarbonized by 2030).

Carbon pricing can be scaled up through carbon surcharges that raise effective carbon prices - from the surcharge, fuel taxes, and the EU Emissions Trading System (ETS) to a target carbon price by fuel and sector. The carbon prices can be progressively harmonized to enhance cost effectiveness. Effective carbon prices should be defined (especially for road fuels) net of taxes warranted by domestic environmental considerations. Raising all effective carbon prices to $€ 125$ (\$150) per tonne by 2030 imposes a manageable burden on the average household of 1.8 percent of consumption (relative to a baseline with current carbon pricing) — and this burden could be largely offset, for example, through using carbon pricing revenues to reduce labor tax rates while boosting hours worked at the same time. A $€ 125$ carbon price, combined with other current measures, still leaves a shortfall relative to national and sectoral mitigation objectives. Given large uncertainties about the carbon prices that would be consistent with Finland's emissions neutrality goal and possible constraints on the acceptability of carbon pricing, sectoral measures like feebates can be deployed to provide some 'insurance' if the emissions impacts of carbon pricing turn out to be smaller than projected and an important reinforcing role to achieve Finland's stated objectives.

Feebates apply a revenue-neutral, sliding scale of fees on products or activities with above average emission rates and a sliding scale of rebates on products or activities with below average emission rates. Feebates: (i) provide a more flexible and cost-effective approach than regulations; (ii) can provide strong mitigation incentives; (iii) avoid large tax burdens on the average household or firm; (iv) avoid fiscal burdens for the government; and (v) can often build off existing administrative capacity. While they would need to be adapted to the specific circumstances in Finland (perhaps with changes to existing regulations and fees), feebates are attractive for:

- Transportation, where (relative to the current tax system) they provide more finetuned incentives for lower-emission vehicles; 
- Industry, where they provide incentives for cleaner production processes with less concern about competitive impacts and emissions leakage (compared with carbon pricing);

- Buildings where they can reinforce incentives for transitioning to electric heating and more energy efficient appliances;

- Land use, where they provide more comprehensive incentives for carbon storage (in forests and peat land) and can be designed to be fiscally neutral (in contrast to afforestation subsidies now under consideration); and

- Agriculture, where they promote shifting to less emissions-intensive practices (indirectly taxing emissions is an alternative though, to avoid leakage, it would need reinforcing at the consumer level, for example with fiscal incentives for plant and poultry-based diets over meat and dairy diets).

\section{A well-designed package of fiscal measures to promote the transition to carbon neutrality in Finland while addressing adverse impacts on households and competitiveness could help build momentum inside the EU and globally for similar policies. Table 1 summarizes the main fiscal recommendations of the paper which are designed to support and reinforce the existing policy framework in Finland.}

The paper is organized as follows. The next section provides background on emissions trends and policies affecting Finland at the EU, national, and sectoral level. Section III discusses a package of national and sectoral level fiscal policy reforms to strengthen mitigation incentives in the energy sector. Section IV discusses strategies for addressing the burden of carbon pricing on households and firms. Section V discusses fiscal measures for the forestry and agricultural sectors. Section VI offers brief concluding remarks. 


\section{Table 1. Recommended Package of Fiscal Instruments to Reinforce Finland's Climate Mitigation Strategy}

Sector

Recommended Policy

\begin{tabular}{|c|c|}
\hline Economy-wide & $\begin{array}{l}\text { Impose carbon surcharges on fuels by sector to raise the effective carbon price--the sum of the surcharge, } \\
\text { fuel/carbon taxes, and pricing from the EU ETS (net of taxation warranted for domestic environmental externalities) } \\
\text {-to a target level, progresively harmonized across fuels/sectors. Set the target prices to reach } € 125 \text { per tonne by } \\
2030 \text {. Embed carbon pricing as part of a broader fiscal reform, involving broad reductions in labor income taxes to } \\
\text { boost the economy in a distributionally balanced manner. }\end{array}$ \\
\hline Road transport & $\begin{array}{l}\text { Introduce feebates for passenger vehicles: a sliding scale of fees/rebates applied to vehicles that have } \\
\text { above/below average } \mathrm{CO}_{2} / \mathrm{km} \text {. Incentives can be set aggressively to promote electric vehicles without a fiscal cost } \\
\text { or new tax burden on the average motorist. Raise the diesel tax to the gasoline tax. }\end{array}$ \\
\hline Industry & $\begin{array}{l}\text { Introduce feebates: a sliding scale of fees/rebates on firms with emission rates above/below the industry average } \\
\text { emission rate. Feebates can provide powerful incentives for cleaner production processes without a large tax } \\
\text { burden on the average firm which lessens concerns about competitiveness and emissions leakage. }\end{array}$ \\
\hline Buildings & $\begin{array}{l}\text { Supplement energy efficiency regulations with: (i) tax-subsidy scheme promoting shift from natural gas heating } \\
\text { systems to electric or other clean fuel systems; (ii) feebates to promote more efficient appliances and lighting. }\end{array}$ \\
\hline Land use & $\begin{array}{l}\text { Introduce a nationwide feebate applied to landowners equal to a } \mathrm{CO}_{2} \text { price times the difference between carbon } \\
\text { storage on their land (form forest and peat) in a baseline year and carbon storage in the current year. This } \\
\text { promotes the full range of nationwide responses for increasing storage with no burden on the average landowner } \\
\text { or fiscal cost to the government. Approximate carbon inventories can be assessed using satellite and aerial } \\
\text { imagery and on the ground sampling. }\end{array}$ \\
\hline Agriculture & $\begin{array}{l}\text { Introduce feebates: a sliding scale of fees/rebates applied to the difference between a farm's emissons per acre } \\
\text { and the industry average emissions per acre scaled by farm level acreage. Emissions can be estimated based on } \\
\text { farm-level inputs and default emissions factors. A shift from beef and dairy to poultry and crop-based production } \\
\text { could be reinforced by 'sin' taxes at the consumer level. }\end{array}$ \\
\hline
\end{tabular}

\section{BACKGROUND ON EMISSIONS TRENDS AND POLICIES}

\section{The (COVID) economic crisis has not affected the urgent need for clean energy}

transitions. Global fossil fuel $\mathrm{CO}_{2}$ and other GHGs need to fall rapidly - by about 25 percent below 2018 levels by 2030 to contain future warming to $2^{\circ} \mathrm{C}$, or 50 percent below for the $1.5^{\circ} \mathrm{C}$ target and continue to decline rapidly thereafter. ${ }^{2}$ Global $\mathrm{CO}_{2}$ emissions in 2020 are projected to be about 8 percent lower than in 2019, due to both lower GDP and structural shifts (e.g., more remote working). However, emissions are projected to start rising again from 2021 as economies recover from the crisis and structural shifts are partially reversed (see Figure 1). Latest projections suggest that global emissions in 2030 will be about 20 percent above 2018 levels (albeit moderately smaller than in pre-COVID projections). The crisis has increased the urgency of carbon pricing in the sense that as economies recover, pricing provides the critical signal for ensuring new investment is appropriately allocated across clean energy and other sectors. And pricing provides a revenue stream that is timely given high budgetary pressures.

\footnotetext{
${ }^{2}$ To net zero emissions by around 2050 and 2070 respectively for the $1.5^{\circ} \mathrm{C}$ and $2^{\circ} \mathrm{C}$ targets (IPCC 2018).
} 
Figure 1. Global Fossil Fuel $\mathrm{CO}_{2}$ Emissions

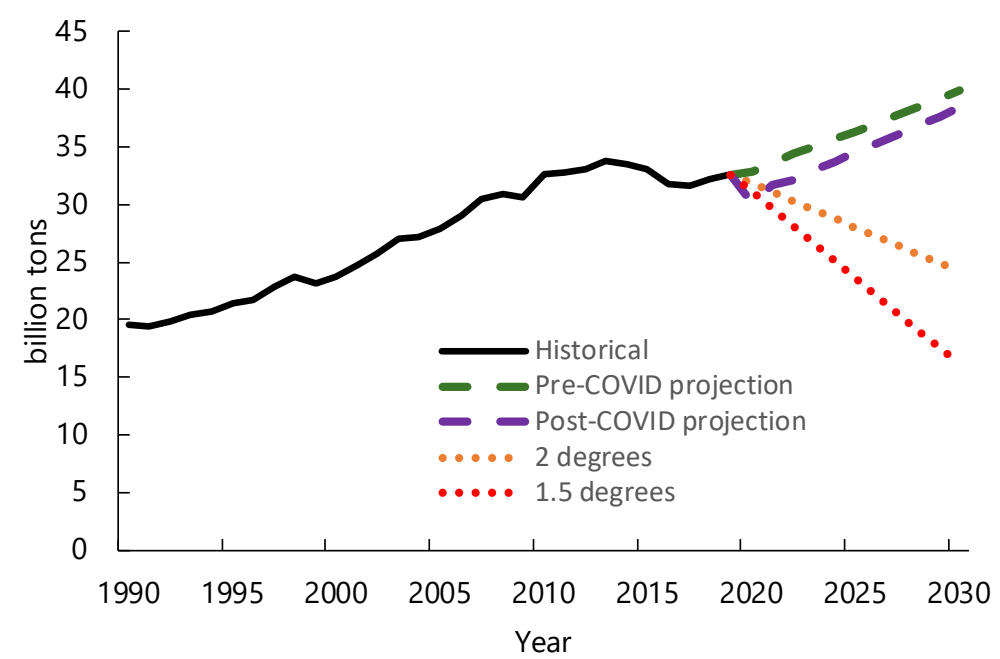

Source: IEA (2020), IMF staff calculations, IPCC (2018).

\section{Figure 2. Trends in Fossil Fuel $\mathrm{CO}_{2}$ Emissions}

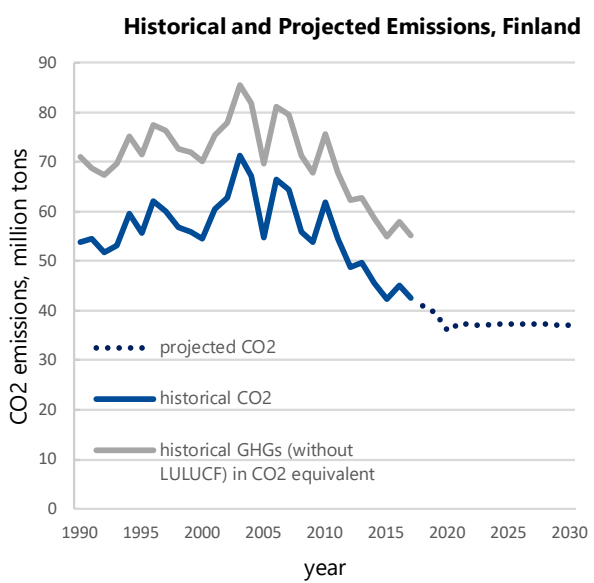

Fossil Fuel $\mathrm{CO}_{2}$ Emissions, 2018

(million tonnes)

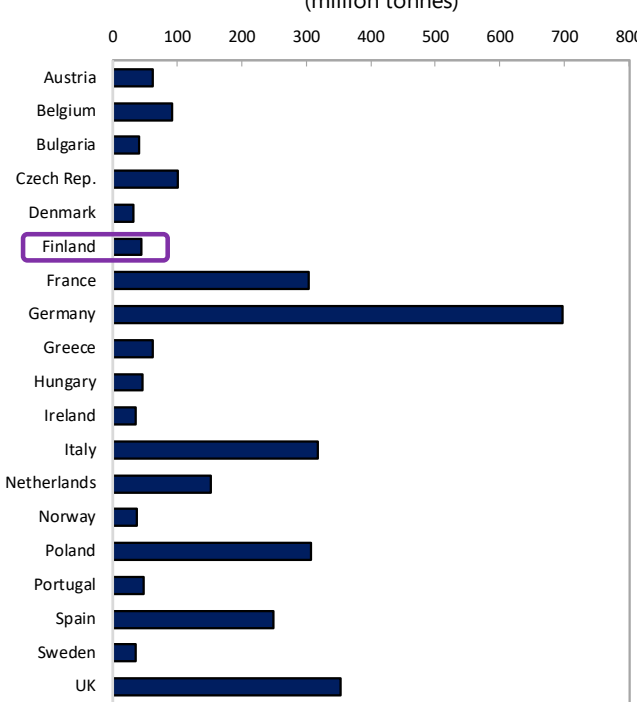

Projected Business as Usual Change, 2018-2030

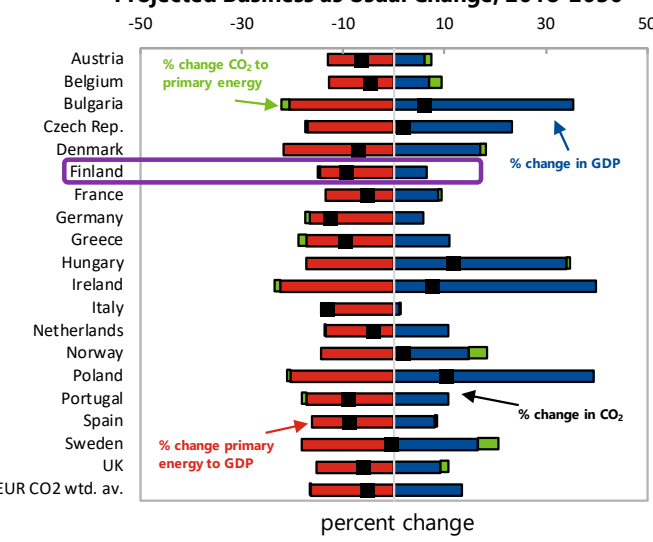

Per Capita $\mathrm{CO}_{2}$ Emissions, 2018

(tons $\mathrm{CO} 2 /$ individual)

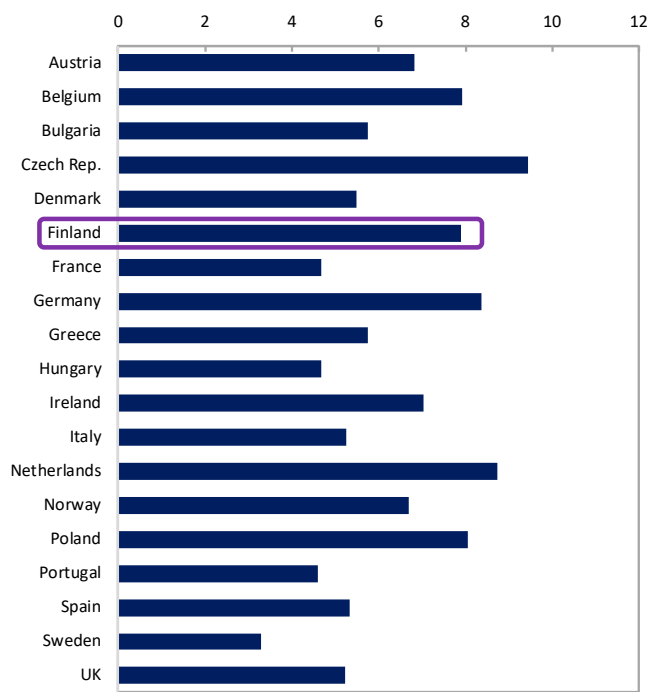

Source. Staff calculations, https://di.unfccc.int/detailed_data_by_party, IEA. Note. Top left figure decomposes the percent change in BAU emissions into the change in GDP, the change in the energy intensity of GDP, and the change in the emissions intensity of energy. 
Finland has cut its GHGs by about a fifth since 1990 though emissions per capita are above average compared with other $\mathbf{E U}$ countries. In a business as usual (BAU) scenario (with current mitigation policies frozen) ${ }^{3}$ IMF staff project emissions are flat after 2020 as trend reductions in the energy intensity of GDP offsets the effect of expanding GDP (the same trends apply broadly in most other European countries). Fossil fuel $\mathrm{CO}_{2}$ emissions in Finland were 8 tonnes per capita in 2018, about the same as in Germany, Netherlands, and Poland, but somewhat higher than in many other European countries. ${ }^{4}$ See Figure 2.

Finland has made an ambitious national pledge to become GHG neutral by $2035 .{ }^{5}$ By this year annual GHG emissions should be 21 million tonnes (Mt) of $\mathrm{CO}_{2}$ equivalent, including both the ETS and 'effort sharing' (other) sectors - a reduction of 70 percent below 1990 levels (71 $\mathrm{Mt} \mathrm{CO}_{2}$ equivalent). This is the amount of emissions projected to be absorbed by carbon sinks - primarily forestry (but also crops, grassland, and wetlands) - on an annual basis in 2035 (see Figure 3). Finland's target (assuming a linear emissions reduction pathway) implies a cut of 55 percent below 1990 levels in 2030, which is consistent with the recently strengthened EU emissions target. Besides Finland, Denmark and the UK have more ambitious national goals than the EU for cutting emissions70 and 68 percent below 1990 levels by 2030 , respectively (Table 2 ). By 2050 Finland has pledged to reduce emissions to 80 percent below 1990 levels (reaching $14 \mathrm{MtCO}_{2}$ equivalent). GHG emissions in 2018 were $56 \mathrm{Mt} \mathrm{CO}_{2}$ equivalent and,

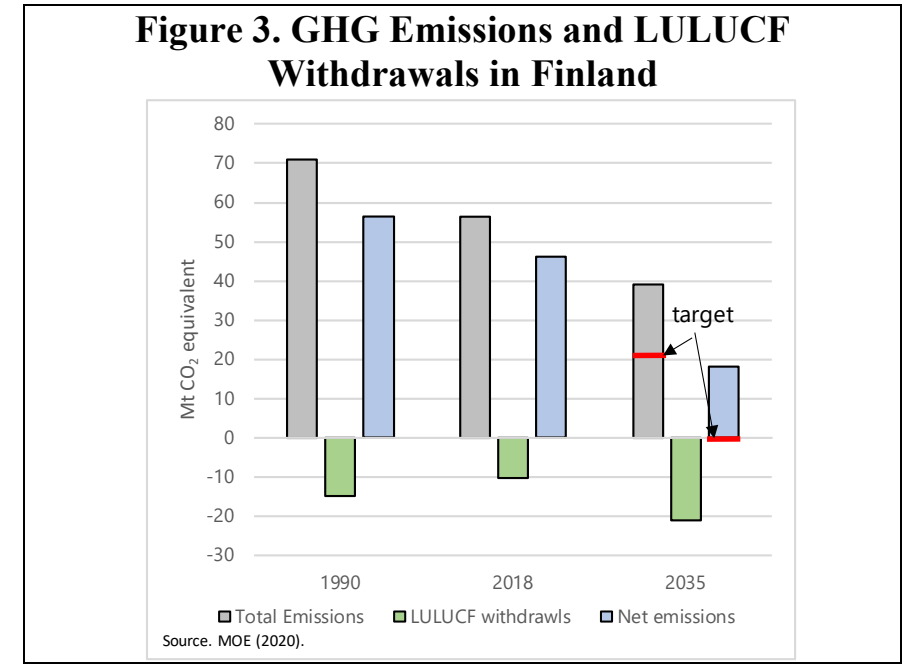

\begin{tabular}{|c|c|c|c|}
\hline & GHG r & $\begin{array}{l}\text { ction be } \\
\text { oercent }\end{array}$ & 1990 , \\
\hline & 2030 & 2035 & 2050 \\
\hline \multicolumn{4}{|l|}{ EU wide targets } \\
\hline Net emissions & 55 & na & 100 \\
\hline \multicolumn{4}{|l|}{ Finland national targets } \\
\hline Net emissions & na & 100 & 100 \\
\hline Emissions (exluding absorprtion from & na & 70 & 80 \\
\hline \multicolumn{4}{|l|}{ Denmark national targets } \\
\hline Net emissions & 70 & na & na \\
\hline \multicolumn{4}{|l|}{ UK national targets } \\
\hline Net emissions & 68 & na & na \\
\hline
\end{tabular}

\footnotetext{
${ }^{3}$ That is, a baseline where fuel mixes are largely unchanged going forward and energy efficiency increases at historical rates.

${ }^{4}$ Cross country comparisons of per capita emissions are however not a reliable indicator of countries' mitigation efforts as they vary, for example, with economic structures and historical dependence on fossil fuels.

5 The 2015 Climate Change Act requires an annual report to Parliament (starting 2019) on emissions trends and achievement of emissions targets - the most recent report is MOE (2020). The Medium-Term Climate Change Policy Plan defines measures for reducing emissions in each sector, such that projected emissions are in line
} 
according to government projections, are estimated at $53 \mathrm{Mt} \mathrm{CO}_{2}$ equivalent in 2019. With existing mitigation policies (WEM scenario), projected emissions for 2035 are $39 \mathrm{MtCO}_{2}$ equivalent, or $36 \mathrm{Mt} \mathrm{CO}_{2}$ equivalent with measures that are planned but not yet implemented. ${ }^{6}$

\section{Land use, land use change, and forestry (LULUCF) emissions were -10.3 Mt $\mathrm{CO}_{2}$} equivalent in 2018 but are estimated at -17.4 Mt $\mathrm{CO}_{2}$ equivalent in 2019. The further increase in absorption will largely come from increasing the average age of forests given limited scope for expanding forest land. ${ }^{7}$ Once age has been optimized, however, forestland does not absorb additional carbon - ultimately other sinks (e.g., direct air capture technologies) will be needed to offset remaining annual emissions. There are methodological challenges related to estimating the size of the LULUCF sink however, and estimates vary considerably from year to year - it is an open question how this variability will be taken into account (e.g., through a multi-period average) when assessing if the emissions neutrality target 2035 is met. ${ }^{8}$ The Finnish government has emphasized emission reductions as the primary way towards achieving the carbon neutrality, but that sinks will need to play a part.

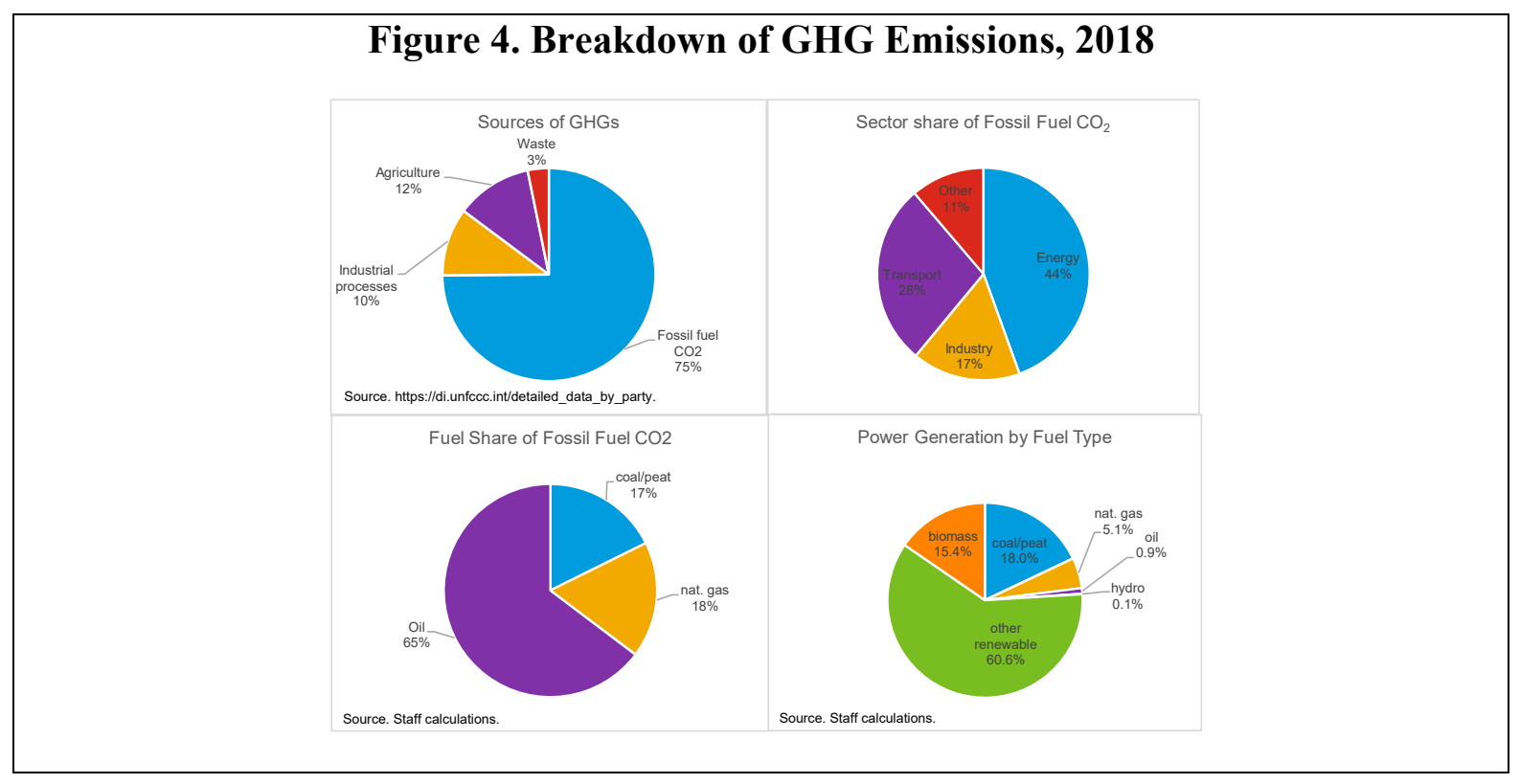

with targets for 2030 in sectors outside the EU ETS. For further discussion of policy options (with less focus on the fiscal instruments considered here) see VTT (2020).

${ }^{6} \operatorname{MOE}(2020)$.

${ }^{7}$ During the growth cycle, temperate forests absorb up to 1 tonne of $\mathrm{CO}_{2}$ per hectare (Mendelsohn and others 2012). This implies, at least, an additional 3.6 million hectares of forestland would be needed by 2035 to increase carbon absorption by 3.6 million tonnes through expanding forest land-forest coverage is already 23 million hectares, or 74 percent of the country's land mass.

${ }^{8}$ Energy emissions projections are also subject to considerable uncertainty. For example, another study for Finland projects emissions will only fall to $44 \mathrm{Mt} \mathrm{CO}_{2}$ equivalent in 2035 under WEM (MOE 2020, pp. 18). 
Fossil fuel combustion accounts for three quarters of current GHG emissions in Finland. Industrial processes (e.g., cement, chemicals) account for 10 percent $^{9}$, agriculture 12 percent and waste (methane leaks from landfills) 3 percent. Energy production (mostly power/district heating) accounts for 44 percent of fossil fuel $\mathrm{CO}_{2}$ emissions, industry (and construction) 17 percent, transportation 28 percent, and other sources (mainly commercial and residential buildings and farm machinery) 11 percent. By fuel type, coal and peat accounts for 17 percent of fossil fuel $\mathrm{CO}_{2}$ emissions, oil 65 percent, and natural gas 18 percent. Biomass (mostly wood) accounted for 15 percent of power generation and other renewables (on- and off-shore wind, solar) 61 percent, while coal/peat and natural gas accounted for 18 and 5 percent respectively.

\section{3 percent of economy-wide emissions in Finland are covered by the EU ETS (just} under the EU average of $\mathbf{4 5}$ percent $^{10}$ ), primarily power/district heat generation and large industrial firms (both $\mathrm{CO}_{2}$ and process emissions). ${ }^{11} \mathrm{EU}$ allowance prices have a history of volatility (Figure 5) though prices have risen and become more stable since the introduction of the Market Stability Reserve (MSR) which withdraws allowances (sometimes permanently) when the amount of banked allowances exceeds a threshold level. As of March 2021, allowance prices are around $€ 45$ per tonne. With a fixed cap on emissions at the EU level, emissions reductions from overlapping policies in Finland would be offset tonnefor-tonne by extra emissions in other EU countries (via a decline in the ETS allowance price). This problem is, to some degree, offset if the MSR is operating. Nonetheless, a more robust and transparent mechanism would be to underpin the EU ETS with an exogenous price floor ramping up over time. ${ }^{12}$ Energy intensive, trade exposed (EITE) industries (e.g., iron/steel, cement, chemicals, refineries, pulp/paper) are granted free allowance allocations to address competitiveness and leakage concerns, though the European Commission is considering replacing this mechanism with a border carbon adjustment (BCA).

\section{7 percent of current GHGs in Finland are from the effort-sharing (i.e., non-ETS)} sector, primarily transport, buildings, and agriculture. Finland is currently required to reduce emissions in the effort sharing sector by 39 percent to $21 \mathrm{Mt} \mathrm{CO}_{2}$ equivalent by 2030 relative to 2005 levels, though this target will be revised following the EU's recently enhanced mitigation pledge. Even the current target is quite stringent and is unlikely to be attained without stronger policy action. ${ }^{13}$

\footnotetext{
${ }^{9}$ Process emissions also include fluorinated gases used in refrigerants and aerosols. These emissions however are projected to drop from current levels of about $1.2 \mathrm{Mt} \mathrm{CO}_{2}$ equivalent to about $0.4 \mathrm{Mt} \mathrm{CO}_{2}$ equivalent in 2030 (MOE 2020, Figure 1.6) due in part to EU regulations (e.g., on emission limits for vehicle air conditioners).

${ }^{10}$ WBG (2020).

${ }^{11} \operatorname{MOE}(2020)$.

12 Price floors might be implemented through allowance auctions with a minimum auction price or making the MSR subject to a price trigger (see Flachsland and others 2018) - either way, allowances should be permanently withdrawn from the system whenever needed to prevent the price falling below the floor.

${ }^{13}$ MOF (2021).
} 


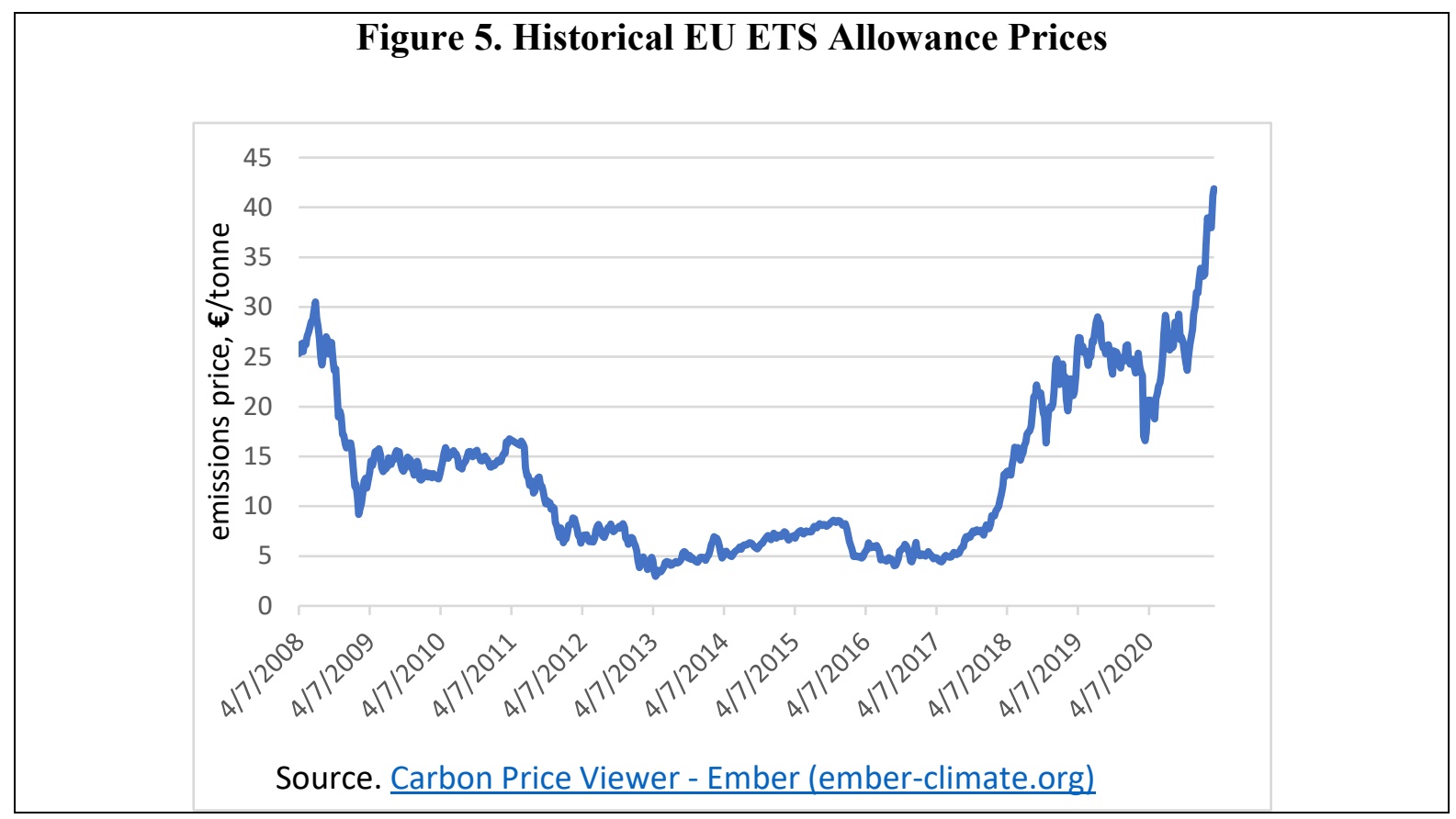

Carbon and fuel taxes are another key instrument for reducing emissions, particularly in Finland's effort-sharing sector. According to OECD estimates (see Table 3), the effective carbon tax for gasoline, diesel, and heating fuels for buildings is currently $€ 77, € 75$, and $€ 62$ per tonne respectively. Additional fuel taxes are equivalent to carbon charges of $€ 234, € 124$, and $€ 29$ on gasoline, diesel, and heating fuels respectively and $€ 10$ and $€ 31$ per tonne for use of coal/peat and natural gas by industry - substantial taxation of road fuels is however warranted by non-carbon externalities (see below). ${ }^{14}$ Finland's carbon tax nonetheless is at the top end of many carbon pricing schemes (Table 4) —only Sweden has significantly higher prices (for non-EU ETS emissions). ${ }^{15}$

\footnotetext{
${ }^{14}$ Taxes in Table 3 refer to 2018 - for comparability, these are used for the core analyses in this paper. The taxes have been revised up in 2021. See Table A1.

${ }^{15}$ Accurate international comparisons of effective carbon pricing are difficult however (MOF 2021), due to challenges of data collection carried out on a voluntary basis in different countries. Also see MOF (2021) for further details on energy taxation in Finland and some reform proposals (e.g., higher heating fuel taxes and the phased removal of tax expenditures on peat and energy tax rebates for agricultural fuels) that are beyond the scope of this paper.
} 
Table 3. Effective Carbon Prices by Major Fuel Type in Finland, €/tonne 2018

\begin{tabular}{lcccc}
\hline \multicolumn{1}{c}{ Sector/fuel type } & $\begin{array}{c}\text { Domestic } \\
\text { carbon tax }\end{array}$ & $\begin{array}{c}\text { Fuel tax (on } \\
\text { energy content) }\end{array}$ & EU ETS charge & Total \\
\hline $\begin{array}{l}\text { Electricity/district heating } \\
\text { Coal and other solid fuels }\end{array}$ & 0 & 0 & 30 & 30 \\
$\begin{array}{l}\text { Industry } \\
\text { Coal and other solid fuels }\end{array}$ & 15 & 10 & 30 & 55 \\
$\begin{array}{l}\text { Natural gas } \\
\text { Road transport }\end{array}$ & 43 & 31 & 30 & 104 \\
$\begin{array}{l}\text { Gasoline } \\
\text { Diesel }\end{array}$ & 77 & 234 & 0 & 311 \\
Buildings & 75 & 124 & 0 & 199 \\
Diesel & 62 & 29 & 0 & 92 \\
\hline
\end{tabular}

Source: MOF (2021), OECD (2019) (updated).

Note. Electricity consumption is also taxed at 2.3 and 0.7 cents/kWh respectively at the household and industrial levels (MOF 2021, Figure 8). Coal used for heating in CHP (combined heat production) plants is subject to excise taxes.

Table 4. Selected Carbon Pricing Schemes, 2020

\begin{tabular}{|c|c|c|c|c|}
\hline \multirow{2}{*}{ Country/Region } & \multirow{2}{*}{$\begin{array}{c}\text { Year } \\
\text { Introduced }\end{array}$} & \multirow{2}{*}{$\begin{array}{l}\text { Price } 2020 \text {, } \\
\text { US } \$ / \text { Ton } \mathrm{CO}_{2}\end{array}$} & \multicolumn{2}{|c|}{ Coverage of GHGs 2018} \\
\hline & & & Million Tons & Percent \\
\hline \multicolumn{5}{|l|}{ Carbon taxes } \\
\hline Chile & 2017 & 5 & 47 & 39 \\
\hline Colombia & 2017 & 5 & 42 & 40 \\
\hline Denmark & 1992 & 26 & 22 & 40 \\
\hline Finland $^{a}$ & 1990 & $75-94$ & 25 & 38 \\
\hline France & 2014 & 50 & 176 & 37 \\
\hline Ireland & 2010 & 22 & 31 & 48 \\
\hline Japan & 2012 & 3 & 999 & 68 \\
\hline Mexico & 2014 & $1-3$ & 307 & 47 \\
\hline Norway & 1991 & 59 & 40 & 63 \\
\hline Portugal & 2015 & 14 & 21 & 29 \\
\hline South Africa & 2019 & 10 & 360 & 10 \\
\hline Sweden & 1991 & 127 & 26 & 40 \\
\hline Switzerland & 2008 & 96 & 18 & 35 \\
\hline \multicolumn{5}{|c|}{ Emissions Trading Systems } \\
\hline California & 2012 & 16 & 378 & 85 \\
\hline China & 2020 & na & 3,232 & \\
\hline European Union & 2005 & 25 & 2,132 & 45 \\
\hline Korea & 2015 & 22 & 453 & 68 \\
\hline New Zealand & 2008 & 17 & 40 & 52 \\
\hline Regional GHG Initiative & 2009 & 5 & 94 & 21 \\
\hline \multicolumn{5}{|l|}{ Carbon price floors } \\
\hline Canada & 2016 & 15 & na & 70 \\
\hline United Kingdom & 2013 & 24 & 136 & 24 \\
\hline
\end{tabular}

Source: WBG (2020), IMF (2019a).

Note. 'Unusually, Finland's carbon tax applies to lifecycle emissions which implies a higher effective tax on combustion emissions--hence the difference between figures in Tables 3 and 4. In addition, carbon tax rates shown above are for Finland's effort sharing sector. 


\section{Road transport accounts for 95 percent of transportation emissions and there are multiple sectoral targets for progressing on decarbonization of the sector. At the EU} level, there are standards for the fleetwide average $\mathrm{CO}_{2}$ emission rates of new passenger vehicles of $95 \mathrm{~g} / \mathrm{km}$ in 2021 with a 37.5 percent reduction in 2030 compared to the 2021 standard. In addition, Finland has set targets to be met by 2030 of: (i) a 50 percent reduction in transportation emissions relative to 2005 levels (and a 100 percent cut by 2045); (ii) a share of biofuels in transportation rising from 20 percent in 2030 to 30 percent in $2030 ;{ }^{16}$ and (iii) 250,000 EVs (either full or plugin) and 50,000 natural gas vehicles on the roads (currently there are 29,000 and 9,000 of these vehicles respectively). ${ }^{17}$ Some of these sectoral targets (e.g., for biofuels) are obligatory while others are planning targets that might be adjusted in future.

Finland's gasoline and diesel fuel taxes are warranted by the full range of local environmental costs from vehicle use. Gasoline and diesel tax are equivalent to $€ 0.70$ and $€ 0.45$ per liter respectively. ${ }^{18}$ Retail gasoline prices for Finland are, nonetheless, about at efficient levels needed to fully reflect supply, environmental costs-including global warming, local pollution, and externalities from traffic congestion, accidents, and road damage - as well as value added tax. Diesel fuel taxes fall short of their (second-best) efficient levels however, due both the lower excise tax and the higher (carbon and local pollution) damage per unit of fuel use. Some of these environmental costs are best addressed through other policies, like peak-period pricing of busy roads for congestion, but it is appropriate to reflect the full range of environmental costs in fuel taxes for the interim until more efficient instruments are comprehensively implemented. ${ }^{19}$ In general, fuel prices in other EU countries also either approximately reflect, or fall somewhat short, of their efficient levels (Figure 6). Local air pollution damages are significant for coal use in Finland though the relevance of this is diminishing with the planned phase out of coal. Local air pollution damages for natural gas are relatively small.

\footnotetext{
${ }^{16}$ See www.businessfinland.fi/en/whats-new/news/2019/finland-sets-new-law-to-increase-biofuel-use-in-roadtraffic.

${ }^{17}$ Finland's passenger vehicle fleet is about 5 million, with a fleet-wide average age of 12.2 years (MOE 2020, pp. 30) and about 115,000 new passenger car registrations in 2019.

${ }^{18} \mathrm{MOF}$ (2021). Finland. In addition, there is an annual propelling-force tax on diesel passenger vehicles which averages $€ 420$ per annum.

${ }^{19}$ See Parry and others (2014) for further discussion on efficient fuel taxes and methodologies for quantifying external costs by country.
} 


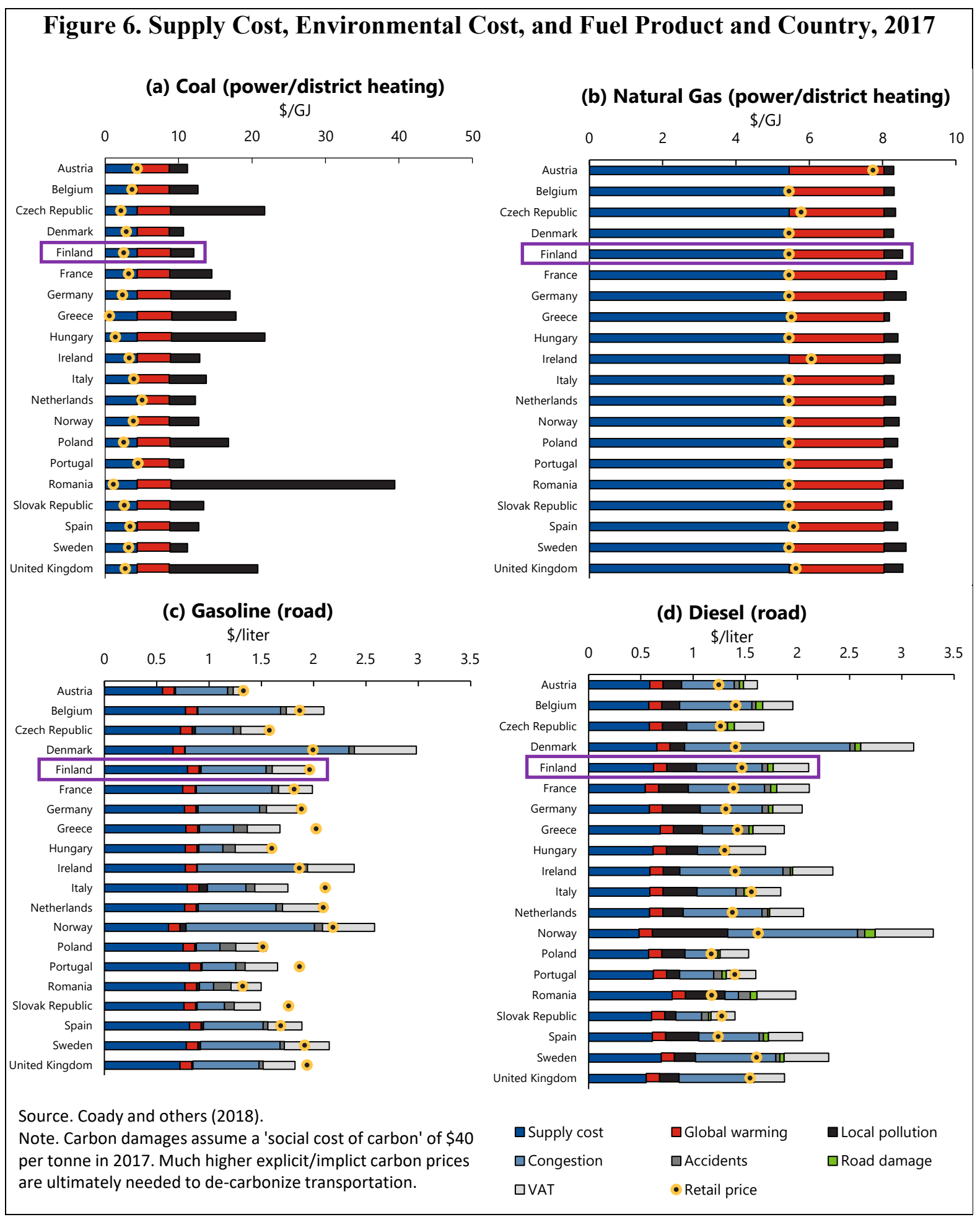

Finland also promotes low emission passenger vehicles though registration fees and annual taxes related to $\mathrm{CO}_{2} / \mathbf{k m}$. Most important are the registration fees that rise from 3 percent to 50 percent of the vehicle price as a vehicle's $\mathrm{CO}_{2}$ emission rate rises from $0 \mathrm{~g} / \mathrm{km}$ to $360 \mathrm{~g} / \mathrm{km}$. The average registration fee paid on gasoline, diesel, compressed natural 
gas (CNG), plug-in EVs and full EVs in 2019 was 15, 19, 9, 4 and 3 percent of vehicle prices respectively - and 15 percent of the vehicle price averaging over all vehicles (Figure 7). If applied to a vehicle with price $€ 30,000$, for example, the average registration fee would have amounted to $€ 4,500$. Registration fees currently raise modest revenues of 0.1 percent of GDP. ${ }^{20}$ Currently there is also a subsidy of $€ 2,000$ for EVs. Vehicles are also subject to annual taxes rising from $€ 53$ to $€ 650$ as the $\mathrm{CO}_{2}$ emission rate rises from $0 \mathrm{~g} / \mathrm{km}$ to $360 \mathrm{~g} / \mathrm{km}$ and above - the average tax across all vehicles is expected to be about $€ 220$ in 2020 , equivalent to about $€ 2,050$ over the vehicle life ${ }^{21}$ (Figure 8 ).

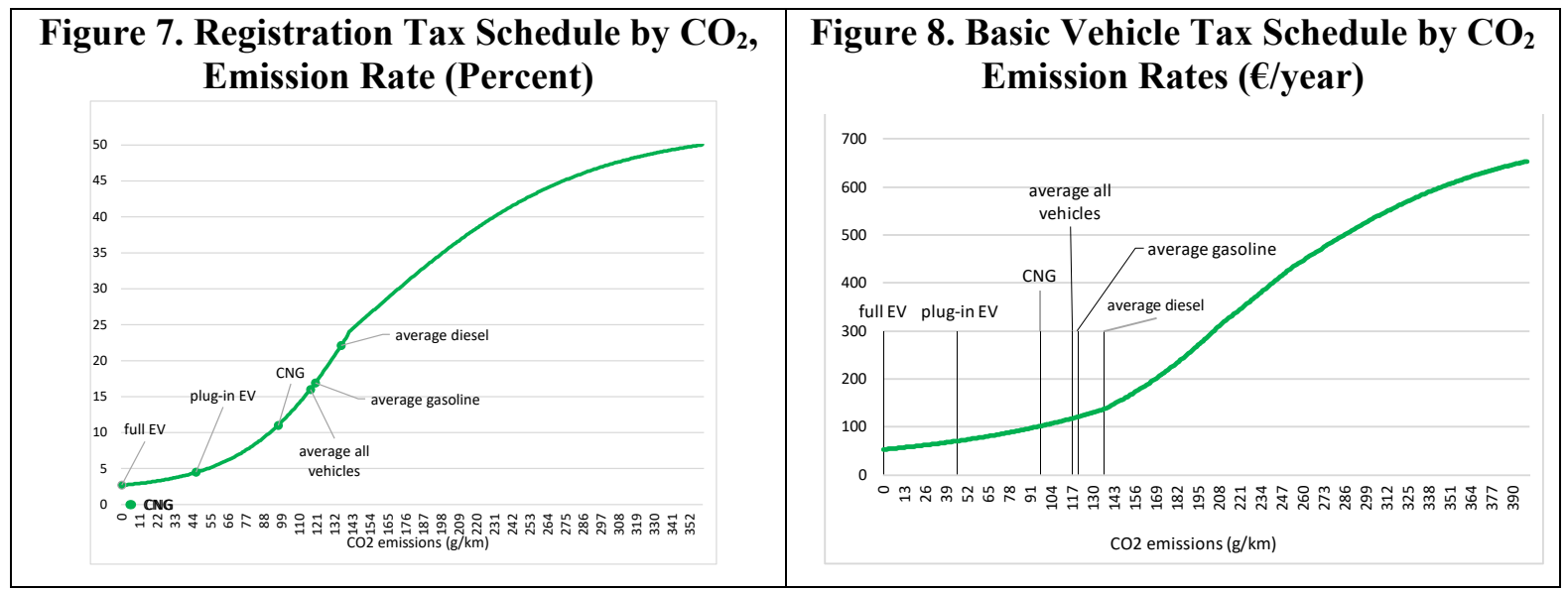

Emissions from space heating declined from 4 to $2.5 \mathrm{Mt} \mathrm{CO}_{2}$ equivalent between 2015 and 2018 and are projected to decline to $1.7 \mathrm{Mt} \mathrm{CO}_{2}$ equivalent by 2030 . ${ }^{22}$ These trends reflect declining use of oil-based heating and improving energy efficiency. Oil heating in government buildings will be phased out by 2025 and the government aims to phase out use of fossil fuel heating in all buildings by the early 2030s (e.g., through use of grants for heating conversions and energy efficiency in residential buildings).

\section{Agricultural emissions have remained relatively stable at 8-9 $\mathrm{Mt} \mathrm{CO}_{2}$ equivalent} since 2005 and on current policies are projected to remain at about this level till 2030 . $^{23}$ Envisioned measures for reducing emissions include promoting carbon storage in soils and peatlands, ${ }^{24}$ reducing food waste by an aspirational target of 50 percent by 2030 , and nutrition programs to promote plant-based diets.

\footnotetext{
${ }^{20}$ From http://pxnet2.stat.fi/PXWeb/pxweb/en/StatFin/StatFin_jul_vermak/statfin_vermak_pxt_127f.px.

${ }^{21}$ Assumes a 12-year lifespan and 5 percent discount rate.

22 MOE (2020), Figure 12.

${ }^{23}$ MOE (2020), Figure 11.

24 Through, for example, recycling nutrients and organic matter, incorporating slurry into fields, planting cover on fields in winter, maintaining environmental grasslands and regulating water levels.
} 


\section{Fiscal Incentives for Progressing on National and Sectoral Targets for FOSSIL FUEL EMISSIONS}

\section{A. National Level Carbon Pricing}

Carbon pricing should be the centerpiece of Finland's mitigation strategy, but more robust pricing is needed. Pricing:

- $\quad$ promotes across-the-board behavioral responses to reduce energy and shift to cleaner fuels (by reflecting the cost of carbon emissions in the prices of fuels, electricity, and goods);

- automatically minimizes the costs of these responses (by equalizing the cost of the last tonne reduced across fuels and sectors);

- $\quad$ levels the playing field for clean technology investments (by establishing a robust price signal);

- $\quad$ mobilizes government revenue;

- $\quad$ generates domestic environmental benefits (e.g., reductions in local air pollution mortality, traffic congestion); and

- $\quad$ is easily scaled up from a technical perspective (given institutional capacity for the EU ETS and carbon tax are well established).

Although the ETS and carbon tax together comprehensively cover fossil fuel $\mathrm{CO}_{2}$ emissions in Finland, prices vary substantially across sectors and fuels (Table 3) and do not ramp up in a predictable way. Greater evenness in carbon pricing across sectors and fuels would lower the costs of a given reduction in nationwide emissions, though significant additional taxation of road fuels is warranted by domestic environmental considerations (see above). Higher future emissions prices and more certainty over prices would provide a stronger price signal for redirecting investment towards cleaner technologies (especially investments with high upfront costs and long-range emissions reductions).

Many other EU countries will likely require emissions reductions relative to BAU levels in 2030 that are comparable to, or larger than, those needed in Finland (Figure 9). In part, this reflects the generally slower reductions in BAU emissions projections in most other countries noted above. Aside from coal intensive countries (e.g. Bulgaria, Czech Republic, Poland) the responsiveness of emissions to nationwide pricing (additional to any existing pricing schemes) is broadly comparable to that in Finland. ${ }^{25}$

\footnotetext{
${ }^{25}$ Unless otherwise noted, calculations below are based on an IMF tool which provides country level estimates of fuel use and emissions by major energy sector and estimates the effect of carbon pricing and other mitigation policies using assumptions about the price responsiveness of fuel use. See IMF (2019) for details.
} 


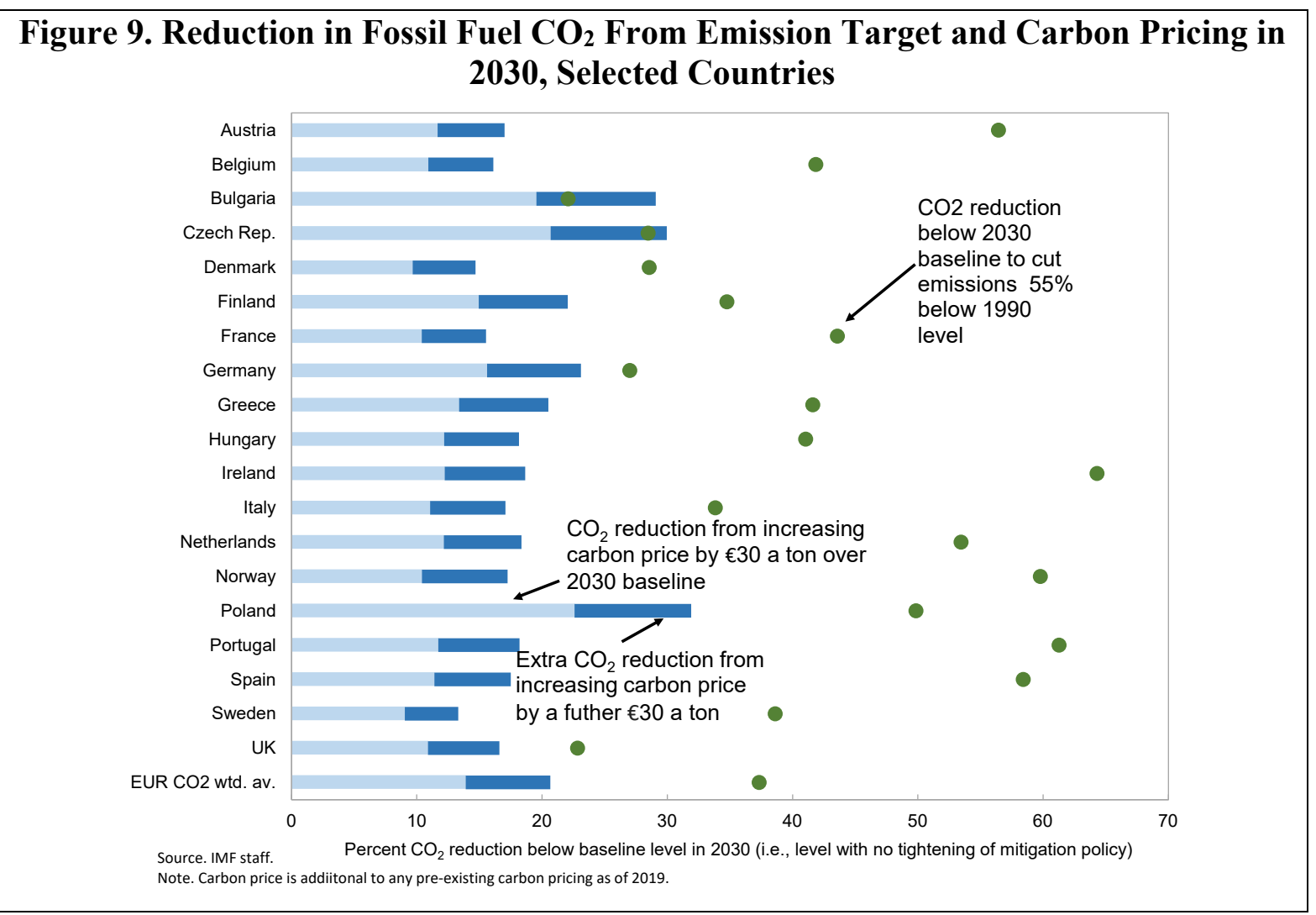

Finland should scale up carbon pricing as much as practically feasible and ideally move towards more even carbon pricing across fuels and sectors. This could be achieved by:

- $\quad$ Setting a target trajectory of future effective carbon prices for each fuel in each sector, over and above any price warranted by domestic environmental considerations;

- Imposing annual surcharges on fuels set such that the surcharge equals the difference between the yearly target price and the prevailing effective carbon price- that is, the combined effect of any domestic carbon tax, fuel tax, and ETS carbon price, less any tax warranted by domestic environmental externalities (a rise in the future EU ETS price would therefore lower the needed surcharge);

- $\quad$ Progressively harmonizing the target carbon prices across fuels (i.e., raising target prices for other fuels up to that for the fuel with the highest target price).

There are precedents for surcharge schemes. A Carbon Price Floor (independent of energy taxation) has been operating in the UK, which imposes a national level variable tax (set three years in advance) on power sector emissions, equal to the difference between an exogenous target price and the projected EU ETS price. ${ }^{26}$ The Netherlands is implementing a similar scheme for its emissions covered by the EU ETS sector (and waste incinerators)

\footnotetext{
${ }^{26}$ See Hirst (2018).
} 
where the planned target price will rise from $€ 30$ per tonne of $\mathrm{CO}_{2}$ in 2021 to $€ 125$ per tonne in 2030. ${ }^{27}$ In line with the Dutch scheme, a carbon price, uniform across fuels and sectors, that ramps up from current effective levels (net of levels to address domestic externalities) to $€ 125$ per tonne by 2030 is considered for Finland (the focus is on 2030 given uncertainty about policies in other EU countries to guide potentially acceptable policies in Finland in 2035). ${ }^{28}$

\section{Increasing nationwide carbon pricing in Finland to $€ 125$ per tonne in 2030 (and freezing it thereafter) in a coordinated way across sectors would, by itself, fall short of what is needed to be on track with national emissions targets. The tax would still leave 2035 emissions at $29 \mathrm{Mt} \mathrm{CO}_{2}$ equivalent or 38 percent above the target level, leaving a significant emissions gap of about $8 \mathrm{Mt} \mathrm{CO}_{2}$ equivalent. ${ }^{29}$}

\section{A $€ 125$ per tonne carbon price in Finland would have relatively modest impacts on revenue, economic welfare, and energy prices. This carbon price would raise extra revenue of 0.3 percent of GDP in $2030 .{ }^{30}$ Economic efficiency costs of the carbon price ${ }^{31}$ amounts to about 0.2 percent of GDP (relative to a zero carbon price). ${ }^{32}$ The higher carbon price would increase natural gas, electricity, and gasoline prices in Finland by $6.5,11.5$ and 8 percent in 2030 relative to 2030 levels with current carbon prices frozen.}

Carbon pricing needs to be reinforced by other, less efficient but likely more acceptable, measures at the sectoral level. A key justification for sectoral measures is that uncertainties over the emissions impacts of carbon pricing increase at higher price levelsother measures can provide some 'insurance' if the emissions impacts of carbon pricing turn out to be smaller than projected. Carbon prices in excess of $€ 125$ per tonne could help to further close the emissions gap, but the risks of a public backlash against pricing are higher with higher price levels, for example, France's planned increase in its carbon tax was suspended in 2018 at $€ 45$ per tonne due to public protests.

The discussion below mostly focusses on feebates-revenue neutral tax-subsidy schemes, which are the fiscal analogue of regulations. Feebates would be applied by finance ministries, whereas regulations are the more natural instrument when climate policy is delegated to environmental ministries. Feebates can, however, be more flexible and cost

\footnotetext{
${ }^{27}$ Government of the Netherlands (2019).

${ }^{28}$ Specifically, emissions prices are increased by $€ 95$ per tonne for coal/peat in both power generation and district heating; $€ 70$ for coal/peat in industry; $€ 21$ for natural gas in industry; $€ 48$ for gasoline; $€ 50$ for road diesel; and $€ 33$ for diesel in buildings. The energy content component of road fuel taxes is assumed to address various (non-carbon) environmental costs (see Figure 6) - the $€ 125$ carbon charge is therefore in addition to the energy tax. Biomass taxation is not considered.

29 This calculation assumes carbon pricing covers 85 percent of future GHG emissions.

${ }^{30}$ Relative to revenue in 2030 under current levels of effective carbon pricing and accounting for erosion of bases for pre-existing fuel taxes.

31 That is, losses in consumer and producer surplus in fossil fuel markets, net of government revenue gains, accounting for pre-existing fuel taxes and emissions pricing.

32 This estimate is based on steady state comparisons and ignores transitional costs, for example, from temporarily idled labor and capital.
} 
effective than regulations - the latter are only cost-effective with extensive credit trading provisions across firms and time. And feebates can be implemented quickly with minimal administrative cost, at least in cases (e.g., transportation, industry, residential heating) where they would build off existing administration for taxes, subsidies, and operating the EU ETS. The discussion below considers transportation, industry, and buildings - the power sector will be largely decarbonized by 2030 .

\section{B. Transportation}

Although Finland's registration fee system provides continuous incentives for loweremission vehicles the environmental incentives are blunted somewhat by relating tax rates to vehicle prices. As EVs currently cost more than their conventional fuel counterparts, relating the tax rate to vehicle price significantly reduces the tax advantage of EVs. Moreover, the more successful the registration fee system is in shifting purchases to low emission vehicles the larger the fiscal burden on the government.

Converting the registration fee and EV subsidy into a pure feebate would sharpen incentives for low emission vehicles while maintaining revenue. A feebate provides a sliding scale of fees on vehicles with above average emission rates and a sliding scale of rebates for vehicles with below average emission rates (including highly efficient petrol and diesel cars). Specifically, under a feebate new (or imported) vehicles would be subject to a fee given by:

$\left\{\mathrm{CO}_{2}\right.$ price $\} \times\left\{\right.$ the vehicle's $\mathrm{CO}_{2} / \mathrm{km}-$ the sales fleet average $\left.\mathrm{CO}_{2} / \mathrm{km}\right\}$ $\times\{$ the average lifetime vehicle use (in discounted $\mathrm{km}$ ) $\}$

Feebates have some attractions over the current registration fee system:

- They sharpen incentives for lower emission vehicles because the absolute tax incentives under the feebate depend only on differences in emission rates between vehicles and not on differences in vehicle prices;

- They automatically maintain revenue neutrality, despite the progressive decarbonization of the vehicle fleet, because the average fleet emission rate in the feebate formula updates (e.g., on an annual or quarterly basis) - current revenues from registration fees (and the average vehicle tax) could be maintained by combing the feebate with a simple lump-sum applied to all vehicles (including EVs);

- $\quad$ They do not require new data or administrative capacity relative to the existing registration fee system (just a recalibration of tax rates); and

- $\quad$ The $\mathrm{CO}_{2}$ price in the feebate can be adjusted if targets for $\mathrm{EV}$ penetration are not being met (though this would require legislation). 
For illustration, a feebates with a price of $€ 800$ per tonne of $\mathrm{CO}_{2}$, combined with a lumpsum tax of $€ 5,500$ to maintain revenue, would subsidize EVs while aggressively taxing high emission vehicles relative to most other European countries (see Figure 10). The scheme would provide a net subsidy of $€ 3,700$ for an EV and apply a fee of $€ 12,000$ to a vehicle with $200 \mathrm{~g} \mathrm{CO}_{2} / \mathrm{km}$. Subsidies for EVs would decline over time as the average fleet emission rate declines, which is appropriate as the cost differential between clean vehicles and their gasoline/diesel counterparts falls

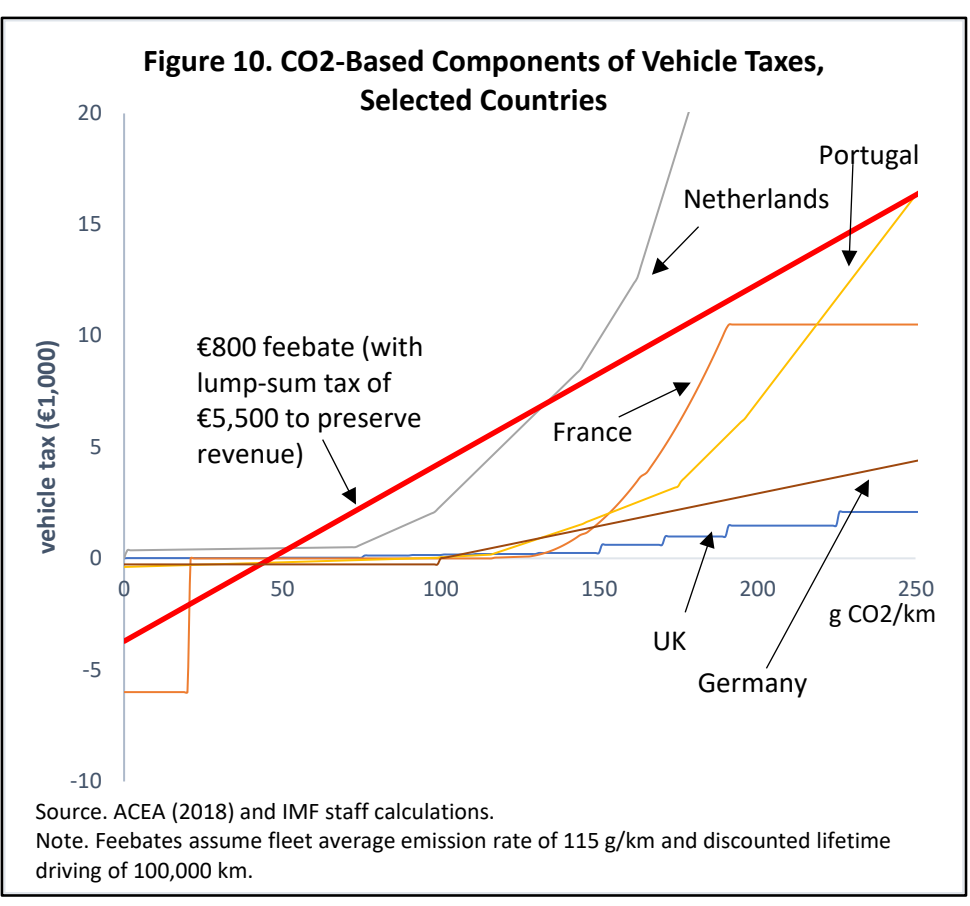
over time (e.g., with improvements in EV battery technology).

A feebate that progressively shifted new sales to 100 percent EVs by 2035 would reduce road fuel emissions about 50 percent below otherwise projected levels for $2035 .{ }^{33}$ Deeper reductions would continue after 2035 as the fleet continued to turn over. ${ }^{34}$

A complementary reform would be to remove the favorable tax treatment of diesel fuel which would improve economic efficiency and generate, albeit moderate and transitional, emissions and fiscal benefits. Although diesel vehicles have higher fuel efficiency than their gasoline counterparts, per unit of fuel use diesel vehicles emit about 16 percent more $\mathrm{CO}_{2}$ emissions. ${ }^{35}$ Raising the road diesel tax by $€ 0.172$ per liter (to increase it to the level of gasoline tax) would increase current pump prices for diesel by 19 percent

\footnotetext{
${ }^{33}$ This calculation assumes 8 percent of the fleet is replaced each year (i.e., vehicle lifespans are 12 years) and initially 2 percent of new vehicle sales are EVs, rising linearly (due to the feebate) to 100 percent by 2035 . Any impact on the overall size of the vehicle fleet should be small as the reform does not affect the price of the average vehicle. Vehicles might be driven more intensively as fuel costs per km decline over time though empirical studies suggest this rebound effect is relatively modest (e.g., Gillingham and others 2015).

34 There is a key role for other complementary policies, for example, provision of EV charging infrastructure, procurement for EVs in public vehicle fleets, and (given the large congestion externalities from all vehicles, including EVs) promoting a modal shift to public transportation, (e.g., MOT 2020, Jochem and others 2016).

${ }^{35}$ Estimated air pollution deaths from diesel fuel combustion are higher than for gasoline consumption. Diesel vehicles directly emit fine particulates (gasoline vehicles do not) which enter the lungs and bloodstream and more nitrogen oxide emissions, which react in the atmosphere to form fine particulates (Parry and others 2014). Diesel vehicles are becoming progressively cleaner however given the stringent EURO VI emission rate standards for new vehicles.
} 


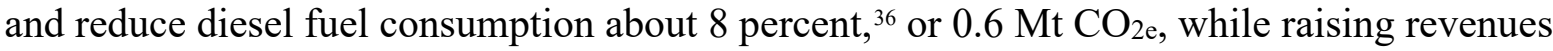
of 0.1 percent of GDP and removing the bias against gasoline vehicles. ${ }^{37}$

\section{Industry}

Feebates could also reinforce incentives for cleaner production processes in carbonintensive industries while limiting concerns about competitiveness and leakage effects. In this case, firms within an industry would be subject to a fee given by:

$$
\begin{gathered}
\left\{\mathrm{CO}_{2} \text { price }\right\} \\
\times\left\{\mathrm{CO}_{2} / \text { output }- \text { industry-wide average } \mathrm{CO}_{2} / \text { output }\right\} \\
\times\{\text { output }\}
\end{gathered}
$$

The feebate, which would apply to direct emissions - from fuel combustion and processes (e.g., production of clinker for cement) ${ }^{38}$ — avoids a first-order tax burden on the average producer (though individual producers paying fees will suffer some loss in competitiveness). This helps to alleviate concerns about competitiveness and leakage impacts compared with a pricing scheme that charges for a firm's remaining emissions (see Appendix I). Again, the scheme could build off existing procedures for monitoring firms' direct emissions under the EU ETS. ${ }^{39}$

Potential applications include metals, forest products, chemicals, and cement/lime production. These industries accounted for about 5, 5, 4, and 3 percent of 2018 nationwide GHGs in Finland respectively. ${ }^{40}$ In cases where the industry is highly concentrated - for example, in Finland there is just one cement producer (with three plants) - a modified feebate might be applied. Firms might be taxed on the difference between their average emission rate, and a target emission rate, with the latter progressively reduced over time (the scheme would converge to an emissions tax as the target emission rate converges to zero). ${ }^{41}$

\footnotetext{
${ }^{36}$ This calculation assumes a fuel price elasticity of -0.5 reflecting reductions in vehicle km driven and improvements in fuel efficiency.

${ }^{37}$ The lifetime cost of using an average diesel vehicle (based on assumptions used above) would increase about $€ 1,400$. A lower level of tax might be warranted for off-road diesel uses (e.g., farm vehicles, construction) which might be implemented through rebates in business tax regimes.

${ }^{38}$ Indirect emissions embodied in electricity inputs are priced under the EU ETS.

${ }^{39}$ The scheme should be compatible with minimum fuel tax requirements under the EU Energy Tax Directive as it effectively imposes additional taxes on the use of fossil fuels while subsidizing clean fuels and technologies.

${ }^{40}$ From http://di.unfecc.int/detailed data by party. Note in the case of forest products, the feebate would reduce the emissions intensity of the production process rather than reduce output of wood products. A separate scheme for promoting forest carbon storage is discussed below.

${ }^{41}$ Whether feebates are consistent with EU state aid rules is not entirely clear. They are, however, operationally equivalent to an emission rate regulation applied uniformly to all firms where firms falling short of the standard buy credits from firms exceeding the standard.
} 


\section{Buildings, Appliances, and Machinery}

Additional market failures may strengthen the case for reinforcing measures in the building sector. For example, renovation rates may be held back by liquidity constraints, cost-benefit mismatches between owners and renters, and unawareness or uncertainty of potential energy savings from renovation. ${ }^{42}$ Actions via both new and existing buildings are needed given the very gradual turnover of the building stock.

Feebates could be used to encourage the phase out of oil-based space heating and (for major product categories) greater energy efficiency. ${ }^{43}$ Revenues from an interim tax on oil heating technologies (with rate increasing through mid-2030s) could fund subsidies for electric heat pumps or hydrogen boilers. And sales of energy-consuming products, such as refrigerators, air conditioners, and industrial machinery, could incur a fee equal to:

$$
\begin{gathered}
\left\{\mathrm{CO}_{2} \text { price }\right\} \times\left\{\mathrm{CO}_{2} \text { per unit of energy }\right\} \\
\times\{\text { energy consumption rate }- \text { industry-wide average energy consumption rate }\}
\end{gathered}
$$

where the energy consumption rate would be based on the product's energy efficiency rating. For refrigerators, for example, the energy consumption rate is $\mathrm{kWh} /$ cubic foot cooled. Besides promoting energy efficiency these schemes also reinforce incentives for use of bio oil and biogas (e.g., in farm vehicles) that reduce the fossil fuel intensity of energy.

\section{Addressing the Burden of Carbon Pricing on Households and Firms}

\section{A. Promoting Equitable Pricing Reform}

Understanding the equity impacts of carbon pricing reform requires household incidence analysis. The household incidence or burden of carbon pricing depends on several channels. ${ }^{44}$ These include: (i) the direct price effect of higher energy prices; (ii) the indirect price effect of higher prices for other consumer goods (due to the higher cost of domestic energy inputs); (iii) changes in wages in trade-exposed sectors that cannot pass forward higher energy input costs to international markets; and (iv) how households benefit from the recycling of carbon pricing revenues. ${ }^{45}$ Finally, all these channels interact with the progressive income tax schedule in Finland, further affecting the overall incidence of carbon pricing reform.

\footnotetext{
${ }^{42}$ See for example Arregui and others (2020), Burke and others (2019).

${ }^{43}$ Promoting electricity conservation is still important, even if power generation were decarbonized, to ensure demand/supply balance given constraints on the availability of renewable generation sites.

${ }^{44}$ See Coady (2006) for a discussion in the closely related context of energy price reforms.

45 The full pass back to wages for exporters is consistent with mobile capital and firms and with exporters being price-takers on world markets. Changes in wages and the return to capital might also result from general equilibrium effects as production is re-allocated from carbon intensive activities to other sectors that may have different capital to labor ratios, but these effects are difficult to predict. As an approximation, it seems reasonable to assume carbon pricing for other (non-trade-exposed) sectors is fully passed forward to domestic users given that (medium to longer term) energy supply curves tend to be fairly elastic. Consistent with this, changes in gasoline and diesel prices tend to be fully passed forward in advanced countries (IMF 2020, pp. 4) while carbon pricing tends to be fully reflected in higher consumer prices for electricity in EU countries (e.g., Sijm and others 2012).
} 
Carbon pricing has a relatively modest impact on energy prices in Finland. ${ }^{46}$ For example (Figure 11), a $€ 125$ per tonne carbon price in 2030 would increase natural gas and road fuel prices by 7.6 and 7.9 percent, respectively relative to BAU.$^{47}$ This would be comparable to the volatility in road fuel prices in Finland over the last 10 years. ${ }^{48}$ Retail electricity prices would rise by 11.5 percent, reflecting the share of zero-carbon fuels in generation and the phase out of coal. While the impact on coal prices is large, coal accounts for a small share of energy consumed by households (excluding district heating).

\section{A higher carbon price affects household welfare, prior to behavioral responses, in} proportion to energy consumption. ${ }^{49}$ The direct impact before tax of an energy price increase resulting from a higher carbon price, expressed as a percentage of total household consumption, can be calculated as: ${ }^{50}$

Pre-tax direct impact $=\{$ budget share $\} \times\{$ percentage increase in energy price $\}$.

If the budget share for a certain energy product is 5 percent for example, a 10 percent increase of the price of this item will result in a decrease in real income for the household equivalent to 0.5 percent. We use Eurostat tables on the structure of consumption expenditure for 48 aggregated categories of goods and services by income quintile for 2015 (the latest available year) and assume these budget shares apply for 2030. Budget shares are adjusted for under-reporting of consumption in household surveys by scaling consumption in the denominator to be equivalent to household consumption in the national accounts. ${ }^{51}$ On average, energy and fuel consumption accounts for 6.3 percent of total household consumption in Finland, slightly lower than in most other European countries (Figure 12).

\footnotetext{
${ }^{46}$ Outcomes are compared in 2030 between BAU with current and announced policies and a scenario with higher carbon tax. The incidence analysis using prices changes in 2035 yields similar results. Carbon pricing increases exclude biomass.

${ }^{47}$ These small price impacts imply that carbon pricing will probably do little to discourage the electrification of transportation and other sectors.

${ }^{48}$ For instance, the standard deviation of the quarterly gasoline retail price index since 2010 has been around 6.5 percent.

${ }^{49}$ Appendix III describes the incidence analysis in detail.

${ }^{50}$ See Coady (2006).

${ }^{51}$ Treatment of imputed rent for owner-occupied housing and some financial services are the main source of discrepancies (see Eurostat 2020 for details). For 2015 in Finland, the ratio of total household consumption expenditure as estimated from the household budget survey to the national accounts was 0.90 .
} 
Figure 12. Household Energy Consumption, By Source

(Percent of Total Household Consumption, 2015)

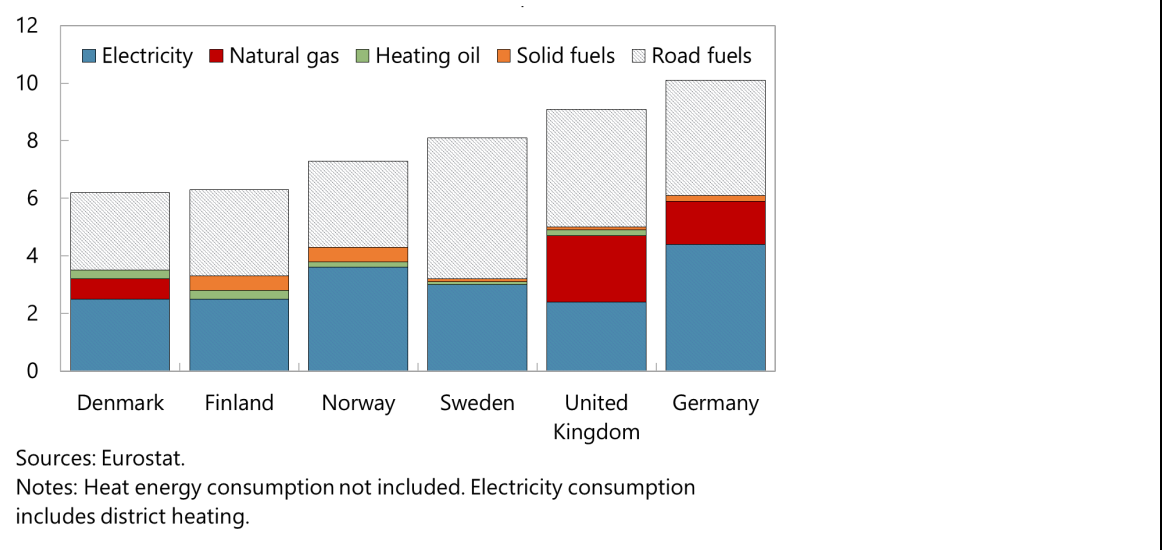

Household energy consumption follows an inverted $U$-shaped pattern across the income distribution in Finland. While electricity and district heat consumption are broadly equal as a share of total household consumption, middle income households spend relatively more on road fuels and solid fuels, including firewood.

Indirect price effects are calculated assuming increases in energy production costs are fully and immediately passed forward onto the domestic prices of goods and services. We use a supply-use table for Finland for 2016 (see Appendix II) to calculate how sectoral prices change in response to higher domestic energy input prices and assume these price impacts would be the same in 2030. These sectoral price changes are then matched to the household consumption tables. The calculations assume the price of non-energy intermediate and final imports stays constant when domestic energy prices increase. This assumes that the increase in domestic carbon prices are not accompanied by the introduction of a BCA. ${ }^{52}$ Importantly, assuming constant household budget shares and energy intensities of production will lead to some overestimate of carbon tax incidence in 2030 as energy efficiency will continue to improve in the future (e.g., due to technological developments).

Households are also affected by changes in wages. Given different energy intensity of production, labor income shares, and exposure to trade, higher energy prices lead to different changes in wages across sectors. ${ }^{53}$ The pass back of higher domestic energy input costs for exporting firms by sector is calculated using the same supply-use table. The associated

\footnotetext{
${ }^{52}$ Under a full BCA with export rebates (see below), the price of imports increases in proportion to their carbon content, while wages paid by exporting firms are unaffected. If foreign production is more carbon intensive than domestic production, then the incidence on households through higher consumer prices would be larger. Accurately estimating this incidence would require inter-country input-output tables with country-sector specific carbon emission intensity of production.

${ }^{53}$ The analysis is done holding real prices constant, so we abstract from indexation of benefits in the calculations of net incomes.
} 
sectoral wage changes multiplied by the share of output that is exported is then matched to household survey data to calculate impacts on different household income groups. ${ }^{54}$

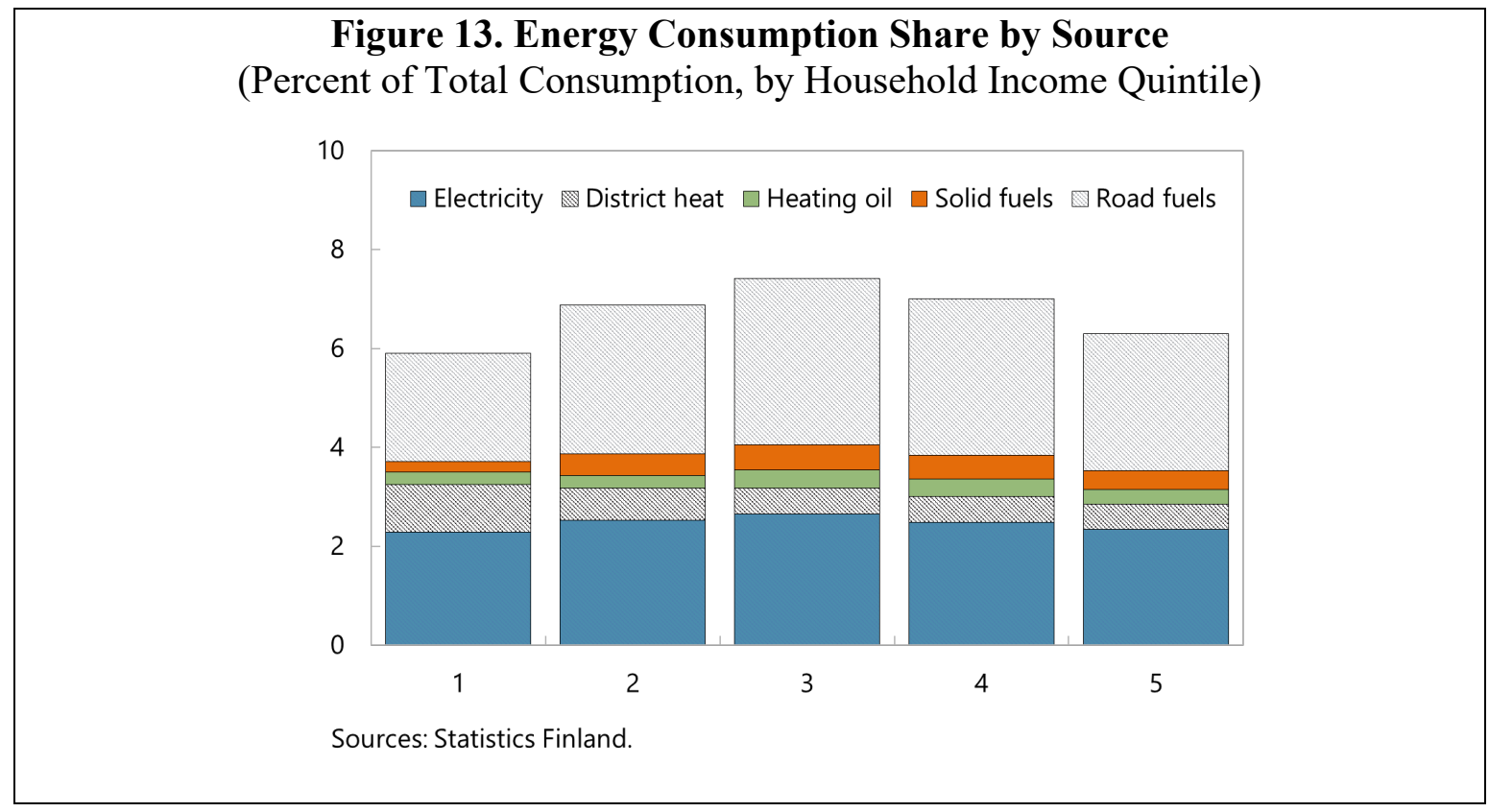

Finally, the income tax in Finland interacts with the price and wage effects to determine the overall burden of the reform. This operates through two distinct channels. First, an increase in consumer prices from the direct and indirect effects only affects the after-tax consumption of households. ${ }^{55}$ For instance, if a household faces an effective average tax rate of 30 percent, higher consumer prices will only apply to 70 percent of its income. The second channel operates through the effective marginal tax rate. If earnings decline as a result of higher carbon pricing - either because wages fall or because higher consumer prices discourage work - then tax liabilities also decline by the amount of the marginal tax rate. The higher the marginal tax rate, the larger the decrease in tax liabilities from lower earnings. Taken together, these two effects offset the negative welfare effects of carbon pricing reform via the price and wage channels. How this offset varies across the income distribution depends on the progressivity of the effective tax schedule in Finland. In particular, if high income households face higher average and marginal tax rates, the tax schedule will shield these households from the full incidence of carbon pricing reform relatively more than lower income households.

\footnotetext{
${ }^{54}$ We use data from the 2017 Income Distribution Survey. Data were accessed via LIS.

${ }^{55} \mathrm{We}$ assume indirect taxes are held constant. See Appendix III for details.
} 
Prior to revenue use, a carbon tax of $€ 125$ per ton of $\mathrm{CO}_{2}$ in 2030 imposes an average burden on households (relative to $\mathrm{BAU}$ ) of 0.9 percent of consumption and follows a U-shape pattern. The purchasing power of households in the lower quintile would decrease by 0.9 percent of total consumption. The main channel contributing to lower real incomes is higher prices for electricity and district heating, lower wages and higher prices for other goods and services. ${ }^{56}$ The progressive income tax schedule in Finland also means that these households face price increases on a larger share of their pre-tax budget compared to other households, since they pay lower taxes on average. At the other end of the income scale, households in the top 20 percent see a similar erosion in purchasing power of 0.9 percent, with almost half of the incidence driven by lower wages. Two factors explain this:

(i) workers in energy intensive and trade exposed sectors such as manufacturing of chemicals, paper and machinery tend to be in households with higher incomes; and (ii) the share of labor income increases along the income ladder. However, the progressivity of the income tax dampens these losses. First, the effective consumer price increase affects a smaller share of these households' income because they face higher average tax rates. Second, their higher marginal tax rates mean the decline in earnings reduces their tax liabilities more than lower income households. Finally, and consistent with Figure 14, middle income households see the largest incidence impact of around 0.97 mainly from lower wages and

Figure 14. Carbon Tax Burden by Source (Percent of Total Household Consumption, by Income Quintile)

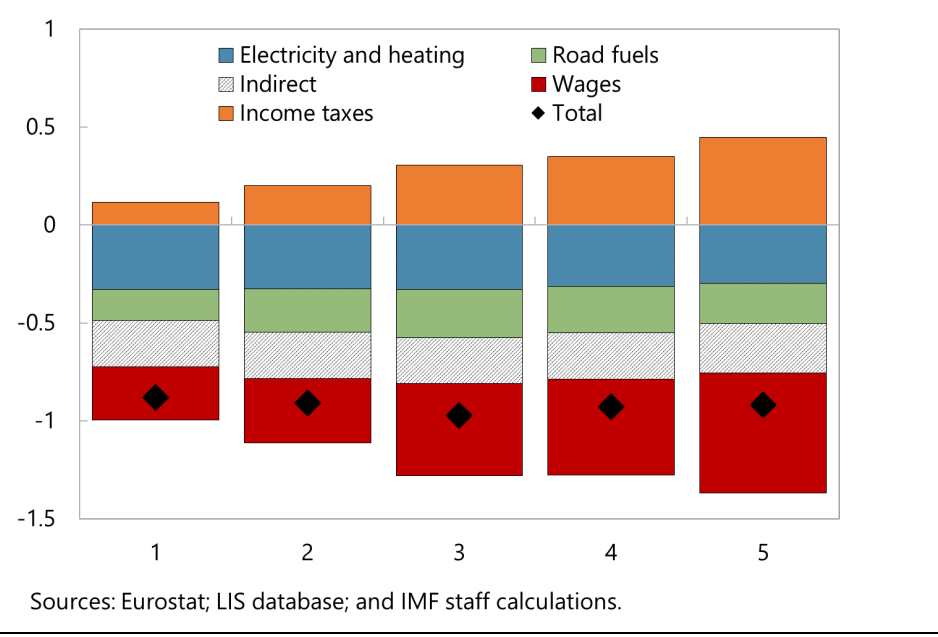
higher prices for electricity and heating. Incomes taxes reduce the total burden, but to a lesser extent than for higher income households.

Alleviating burdens on households can be done at little fiscal cost. In the scenario under consideration, the carbon tax collects around 0.65 percent of consumption in revenues in 2030 (relative to BAU), which falls short of the average incidence by 0.25 percent of consumption. This means that in aggregate, the incidence arising from the carbon tax can be fully offset at fairly modest additional fiscal cost. ${ }^{57}$ This could be done by transferring the proceeds of the carbon tax, along with a modest top up from general funds, back to

\footnotetext{
${ }^{56}$ For instance, higher energy prices are passed on to higher rents.

57 The incidence and compensating reform depend on the time period under consideration. The proceeds of the carbon tax will diminish in time whereas the fiscal cost of a one-time labor tax cut will not.
} 
households in the form, for example, of labor tax cuts. Crucially, the compensating reform would fully protect all household income groups and workers from higher energy prices. ${ }^{58}$

Small reductions in marginal labor tax rates can compensate households for higher prices and lower wages due to the carbon tax. In the long run (about five years ${ }^{59}$ ) with wages determined by constant returns to labor and capital, the labor income tax reform would reduce marginal tax rates by roughly 0.8 percentage point for most workers compared to the current schedule. ${ }^{60}$

Figure 15. Marginal Tax Rate Schedules for Labor Income

(Percent, by Income Quintile)

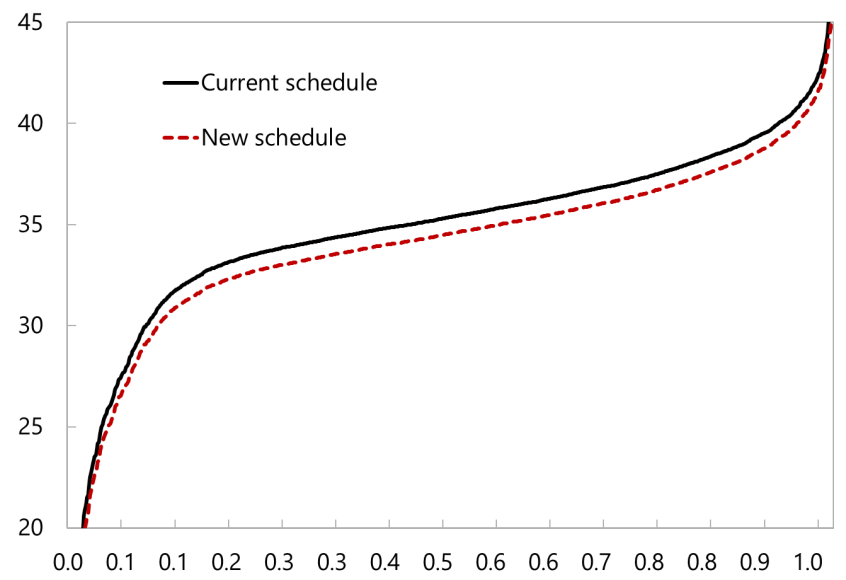

Sources: Eurostat; LIS database and IMF staff calculations.

Using carbon tax revenues to reduce marginal labor income tax rates would have a positive impact on hours worked and counteract the adverse employment effects of higher energy prices. In the scenario considered, hours worked decline by around 0.6 percent as the carbon tax is passed forward to higher domestic consumer prices (and therefore lower real returns to work effort) and passed back through lower wages in exporting firms. ${ }^{61}$ When the proceeds of the tax are used to reduce marginal labor tax rates in

\footnotetext{
58 The analysis assumes wages fully respond to energy price increases over the next 10 years so that it doesn't lead to higher unemployment. The specific parameters of the reform will depend on household's real income changes, the elasticities of labor supply and demand and features of the income distribution (Tsyvinski and Werquin 2019).

${ }^{59}$ Holmlund and Soderstrom (2011).

60 The simulations assume a long-run labor supply elasticity of 0.5 while labor demand is assumed to be flat, consistent with constant returns to labor and capital. The current (average) marginal tax rate schedule is estimated by a functional relation using microdata from the Survey on Income and Living Conditions 2016 (see Appendix III and Tsyvinski and Werquin 2019 for details).

${ }^{61}$ See Appendix III for details on the simulations.
} 
a way that compensates households for their initial welfare loss, the decline in hours worked is reversed and hours worked do not change on net. ${ }^{62}$

Other transfer schemes offer different equity-efficiency tradeoffs. The compensating tax reform outlined above can be compared for instance to an alternative transfer policy where the proceeds of the tax are given back lump sum to households. This scheme would further reduce inequality as consumption in the bottom quintile would increase on net by around 0.9 percent on average and decrease by 0.6 percent of consumption for households in the top quintile. However, there would be no employment benefits since marginal tax rates would not be reduced. Alternatively, the bottom quintile could be fully compensated through transfers using around 30 percent of the carbon pricing revenues. This approach would improve the ex-post progressivity of the reform, but would increase inactivity traps. This could lower overall labor supply compared with full recycling of carbon tax revenues through marginal tax rate reductions. Several other reforms are possible, for example raising in-work benefits for low-wage workers. ${ }^{63}$ Choosing any specific reform will ultimately depend on society's values and preferences over equity and efficiency.

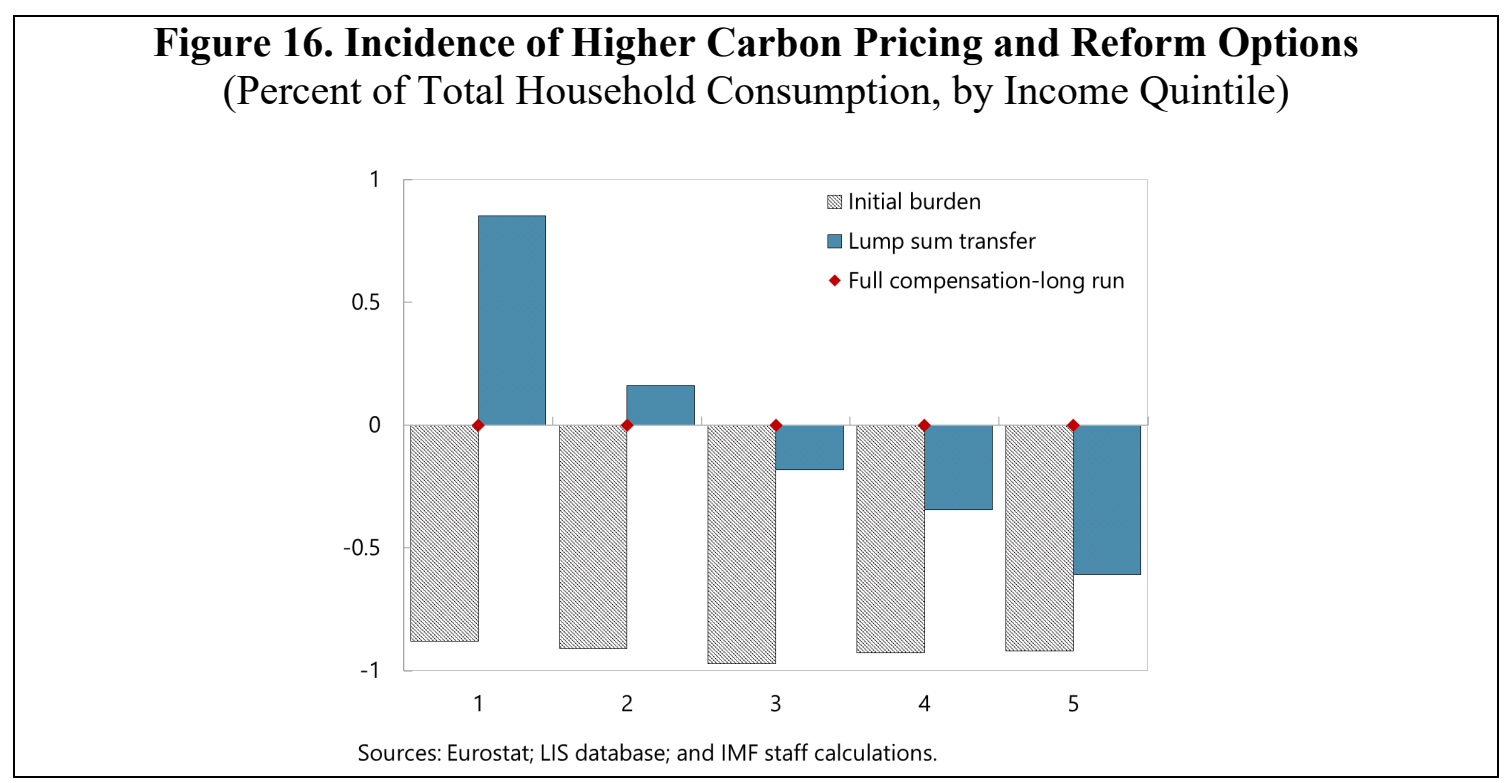

\footnotetext{
${ }^{62}$ Recall that the reform scenario assumes labor tax cuts that exceed the carbon tax revenues themselves to compensate everyone for the increase in carbon pricing. The impact on total output is therefore lower than the increase in labor supply. Diamond and Mirrlees (1971)'s production efficiency theorem states that the overall impact would be negative under general assumptions.

Carbon tax reform could also bring co-benefits in terms of lower local air pollution (Parry and others 2015). In addition to the positive health effects, there is also evidence this could increase labor productivity (Graff Zivin and Neidell, 2012).

${ }^{63}$ This reform would lower average tax rates for workers rather than marginal rates - the former encourages labor force participation, but not extra hours worked on the job. Empirical labor supply studies find however that most of the labor supply elasticity is due to the former response.
} 


\section{B. Carbon Pricing, Leakage, and Competitiveness}

The European Commission is considering the possibility of an EU-level BCA. ${ }^{64} \mathrm{~A} \mathrm{BCA}$ is a charge on embodied carbon in products imported into a jurisdiction with a carbon pricing scheme, perhaps matched by rebates for charges on embodied carbon in exports from the jurisdiction. The BCA could either be an import tax/export subsidy or a requirement for importers to purchase allowances (perhaps from a separate pool than a domestic ETS to prevent upward pressure on domestic emission prices) with exemptions from the scheme for exporters. ${ }^{65}$ Currently, concerns about the impact of carbon pricing on the competitiveness of EITE industries (e.g., cement, refining) and leakage are addressed through granting them free allowance allocations under the EU ETS. But this mechanism will lose viability with deeper decarbonization of industry (Appendix I) which is one reason for the interest in BCAs. ${ }^{66}$

Carbon leakage can come from changes in global trade patterns. This would occur as higher energy input costs cause domestic firms to lose market shares both domestically and abroad to foreign competitors in lower-taxed jurisdictions. High domestic carbon prices may then lead to import substitution of emission-intensive goods weakening the impact of unilateral mitigation policies on global emissions. Coordinated policies can limit the extent of leakage because intra-EU trade flows are not affected to the same extent when national carbon price policies are coordinated.

\section{Staff estimates suggest carbon} emissions leakage is significant at the EU-level, and considerably more so for small, open economies like

Finland. Misch and Wingender (2021) use sectoral variation in energy prices to recover ex post estimates of carbon leakage resulting from energy price changes. Panel data on the carbon content of trade allows them to look at a broader measure of carbon flows than previous empirical research that has mainly focused on industry case studies or migration of energyintensive firms (rather than all firms). The simple average leakage rate from increases in energy prices across the

\section{Figure 17. Carbon Leakage Rate of National Policies}

(Share of Domestic Reduction Offset Abroad)

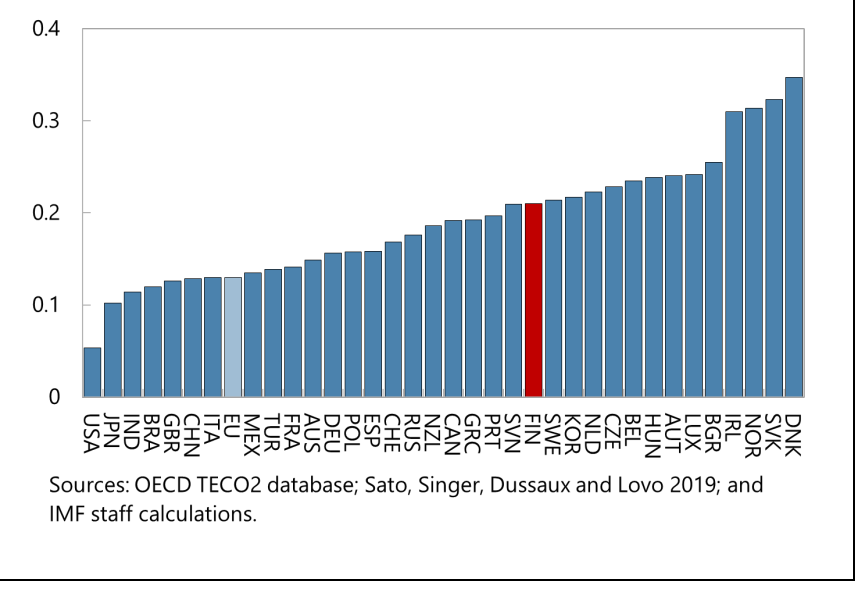
37 countries and 21 industrial and energy sectors covered in the sample is around 0.2 . It is lowest for some of the largest countries such as the US, China and India and tends to be larger for small open economies. The estimated leakage rate - the share of emissions reduction that shifts abroad as a result of more stringent energy and carbon pricing-for

\footnotetext{
${ }^{64}$ See also Carbon Border Adjustment Mechanisms and Their Economic Impact on Finland and the EU.

${ }^{65}$ Adopting an import tax arrangement in the context of a BCA would require unanimity given the existing EU legal framework. Only a qualified majority of Member States would be needed for the adoption of the BCA through the EU ETS, making this option more likely. The EU proposal is expected to be released in June.

${ }^{66}$ The empirical literature on carbon leakage and the competitiveness cost of carbon pricing is inconclusive. While the effects of existing regulations and carbon pricing schemes are small, they are largely uninformative about the impacts of the much more ambitious policies considered here. Misch and Wingender (2021) provide a review of the small but growing empirical literature.
} 
Finland is 0.2 (a consequence of high trade openness in embedded carbon) while the leakage rate for the EU-wide policies is 0.13 .

\section{A feebate may be a more efficient instrument for limiting leakage and competitiveness concerns than free allowance allocation but a BCA could be more efficient still. A} feebate imposes a smaller burden on industries than carbon pricing as there is no transfer payment or charge for firms' remaining emissions, but it does not promote the entire range of behavioral responses for reducing emissions (Appendix I). Under free allowance allocation the transfer payment is neutralized, but there is a broader cost on the economy as this approach diverts revenue from the general budget, revenue that might have been used to cut marginal tax rates to counteract the harmful employment effects of higher energy prices. Rather than offsetting cost increases for domestic firms, instead a BCA raises costs for imported goods to address competitiveness and leakage effects. Unlike a feebate, it promotes the full range of mitigation responses, and unlike free allowance allocation it does not use up valuable revenues - in fact it raises additional revenue.

There are several key issues to consider in designing a BCA though practical options should be feasible. The issues are summarized in Table 5 and Appendix III provides further discussion.

\section{Table 5. Key Design Issues for BCAs: A Summary}

\begin{tabular}{|c|c|c|c|}
\hline Design issue & Administrative considerations & Mitigation incentives & Other comments \\
\hline Industry coverage & $\begin{array}{l}\text { Extending coverage to non-EITls } \\
\text { would increase administrative } \\
\text { burdens... }\end{array}$ & $\begin{array}{l}\text {....and provide little addiitonal } \\
\text { mitigation incentives for overseas } \\
\text { exporters due to the low emobodied } \\
\text { carbon in broader product classes. }\end{array}$ & $\begin{array}{l}\text { Full industry coverage would be } \\
\text { consistent with pricing emissions } \\
\text { embodied in domestic consumption } \\
\text { rather than, as in the Paris framework, } \\
\text { emissions released within national } \\
\text { borders. }\end{array}$ \\
\hline $\begin{array}{l}\text { Country } \\
\text { benchmark for } \\
\text { embodied carbon }\end{array}$ & $\begin{array}{l}\text { Measuring embodied carbon } \\
\text { according to the overseas exporting } \\
\text { country (rather than domestic } \\
\text { industry) complicates } \\
\text { administration... }\end{array}$ & $\begin{array}{l}\text {...but provides incentives for } \\
\text { governments of overseas exporting } \\
\text { countries to strengthen mitigation } \\
\text { policy. }\end{array}$ & $\begin{array}{l}\text { Measures of embodied carbon at the } \\
\text { industry level are publicly available } \\
\text { for most countries. }\end{array}$ \\
\hline $\begin{array}{l}\text { Rebating domestic } \\
\text { exporters }\end{array}$ & Modest administrative burden. & $\begin{array}{l}\text { Removes mitigation incentives for } \\
\text { domestic exporters (which } \\
\text { moderately offsets efforts to meet } \\
\text { Paris pedges for domestic emissions). }\end{array}$ & $\begin{array}{l}\text { Modestly reduces revenue from } \\
\text { domestic carbon pricing. }\end{array}$ \\
\hline Revenue use & $\begin{array}{l}\text { Alternative revenue uses have little } \\
\text { implication for administrative } \\
\text { burdens. }\end{array}$ & $\begin{array}{l}\text { Using revenues for domestic green } \\
\text { investment or international climate } \\
\text { finance would enhance mitigation. }\end{array}$ & $\begin{array}{l}\text { Using some revenue for international } \\
\text { climate finance/rebates to overseas } \\
\text { governments could help with CBDR- } \\
\text { CR and lower risk of retaliation/WTO } \\
\text { ruling BCA is a protectionist measure. }\end{array}$ \\
\hline $\begin{array}{l}\text { Adjusting import } \\
\text { charge for carbon } \\
\text { pricing overseas }\end{array}$ & $\begin{array}{l}\text { Modest administrative burden } \\
\text { (though procedures may be needed } \\
\text { to detect re-labelling pre-eixting fuel } \\
\text { taxes as carbon pricing). }\end{array}$ & $\begin{array}{l}\text { Incentive for governments in } \\
\text { exporting country to increase carbon } \\
\text { pricing--not least, this enables them } \\
\text { to capture the tax base on their own } \\
\text { emissions. }\end{array}$ & $\begin{array}{l}\text { For competitiveness considerations, } \\
\text { overseas pricing needs to cover } \\
\text { power generation/industry. For } \\
\text { promoting effective carbon pricing it } \\
\text { should also cover } \\
\text { transport/buildings. }\end{array}$ \\
\hline $\begin{array}{l}\text { Rebating for } \\
\text { individual overseas } \\
\text { exporters with } \\
\text { embodied carbon } \\
\text { below their } \\
\text { industry average } \\
\end{array}$ & $\begin{array}{l}\text { Modest administrative burden. Onus } \\
\text { would be on overseas firms to } \\
\text { demonstrate lower embodied carbon. }\end{array}$ & $\begin{array}{l}\text { Provides mitigation incentives for } \\
\text { individual exporters. But may also } \\
\text { cause shifting of sales from emissions } \\
\text { intensive firms/plants to countires } \\
\text { without pricing. }\end{array}$ & $\begin{array}{l}\text { Third party data sources might } \\
\text { validate embodied carbon at } \\
\text { firm/plant level. }\end{array}$ \\
\hline $\begin{array}{l}\text { Differentiating } \\
\text { charges by country } \\
\text { income }\end{array}$ & $\begin{array}{l}\text { Modest additional administrative } \\
\text { burden. }\end{array}$ & $\begin{array}{l}\text { Lowers penalty for insufficient pricing } \\
\text { in non-advanced countries but more } \\
\text { consistent with CBDR-RC principle. }\end{array}$ & $\begin{array}{l}\text { Only partially addresses } \\
\text { competitiveness/leakage. But may } \\
\text { lower risk of trade retaliation, or even } \\
\text { withdrawal from Paris Agreement, by } \\
\text { non-advanced countries. }\end{array}$ \\
\hline
\end{tabular}




\section{Mitigation Policies for Forestry ANd Agriculture}

\section{A. Promoting Carbon Storage from Forestry and Land Use Changes}

Forestry and land use policies should promote, nationwide, the main channels for increasing carbon storage. These include: (i) reducing deforestation- the main driver behind the LULUCF sink is how much forest is annually cut down for the forest industry; (ii) afforestation; and (iii) enhancing forest management (e.g., planting larger trees, fertilizing, tree thinning, increasing rotation lengths). Exploiting the full range of opportunities, nationwide, for scaling up carbon absorption is important, if emissions neutrality is to be achieved by 2035 , given the impracticality of cutting GHG emissions to zero. To the extent forest coverage is expanded this can, moreover, generate other environmental co-benefits beyond carbon storage such as reduced risks of water loss, floods, soil erosion, and river siltation. On the other hand, if increased storage comes at the expense of longer rotations and reduced timber supply for construction materials, this could have the perverse effect of increasing $\mathrm{CO}_{2}$ emissions through additional use of steel and cement. ${ }^{67}$

A national feebate program could cost-effectively promote all responses for increasing carbon storage without a fiscal cost to the government. The policy would apply, to landowners - most importantly those at the agricultural/forestry boundary - a fee given by:

$\left\{\mathrm{CO}_{2}\right.$ rental price $\}$

$\times\{$ carbon storage on their land in a baseline period- stored carbon in the current period $\}$

This scheme would reward all three channels for enhancing carbon storage, either through reduced fees or increased subsidies (unlike an afforestation subsidy which just rewards one channel). Periods here could be defined as averages over multiple years given that carbon storage might be lumpy during years when harvesting occurs. Feebates can be designedthrough appropriate scaling of the baseline over time ${ }^{68}$ - to be revenue-neutral in expected terms (again, unlike an afforestation subsidy). And a feebate could be administered by the Ministry of Finance based on the registry of landowners used for business tax collection. Landowners who anticipate receiving rebates may offer political support for the program. Feebates have not previously been used in the forestry sector but they bear partial resemblance to environmental services payments programs that were first introduced in Costa Rica. ${ }^{69}$

Feebates should involve rental payments, rather than large upfront payments for tree planting, given that changes in carbon storage may not be permanent. The problem with one-off, upfront payments is that afforestation may be reversed-for example, a new tree farm receiving an upfront rebate may be subsequently harvested or destroyed (by fires, pests,

\footnotetext{
${ }^{67}$ Longer rotations might lessen the need for regulations on minimum ages for tree cutting.

${ }^{68}$ See Parry (2020) for details.

${ }^{69}$ See, for example, www.fonafifo.go.cr/en. Costa Rica's scheme involves payments to develop and maintain forests (but does not apply fees for reductions in forest coverage).
} 
windstorms), requiring complex, ex-post re-payment procedures to provide adequate incentives for maintaining the land-use change. Rental payments should equal the product of the carbon price times, the interest rate, and the number of years in a period..$^{70}$ The carbon price would need to rise over time to provide ongoing (rather than one off) increases in carbon storage. Partial exemptions from fees may be warranted for timber harvested for wood products (e.g., furniture, houses) because the carbon emissions (released at the end of the product life) will be delayed, perhaps by several decades or more.

Feebates have become more practical with advances in monitoring technologies. Forest carbon inventories are estimated through a combination of satellite monitoring, aerial photography, and on-the-ground tree sampling. Satellite pictures can be used to measure forest coverage and over time reveal visible land use changes like clear-cutting of intact forest. Carbon storage per hectare of forested land is more difficult to verify however, as it varies with land productivity, tree species, and forest management practices (e.g., selective harvesting can reduce stored carbon without visible clear cuts). Low-level aerial photography along forest boundaries, using technologies like Light Detection and Ranging (LIDAR), can estimate wood volume (therefore implicitly account for selective harvesting and changes in forest management) much more cheaply than on the ground sampling. However, on-theground sampling (the most expensive technology) is still needed for densities below a certain threshold. Administrative costs might be kept down by, for example, limiting sampling to once every several years ${ }^{71}$ and building off regulatory approval procedures for tree harvesting and removal.

\section{B. Agricultural Emissions}

GHG emissions from agricultural production can be reduced through several channels. Reducing the size of livestock herds - particularly beef and dairy cattle, but also pigsreduces methane emissions from enteric fermentation and nitrous oxide emissions from manure and growing crops for animal feed. ${ }^{72}$ Reducing crops for human consumption also reduces nitrous oxide emissions from soils, especially where there is intensive use of chemical fertilizers, and promotes carbon sequestration in land reverting back to its natural state. Use of peat land (currently responsible for half the GHG emissions from agriculture in Finland but accounting for only 10 percent of farmland) could also be reduced - currently subsidies support clearance of peat land for farming. ${ }^{73} \mathrm{CO}_{2}$ equivalent emissions per acre, however, are much lower for crops than livestock - an incentive mechanism that encourages shifting from livestock to crop production will therefore reduce emissions. At the consumer level, shifting from meat and dairy products to plant-based and poultry diets, through changes in the relative price of food products, can reinforce mitigation incentives. To date,

\footnotetext{
${ }^{70}$ Sedjo and Marland (2003).

${ }^{71}$ Measuring above ground carbon only (usually about three quarters of the total) could also keep costs down.

72 Batini (2019). Additives to cattle diets and manure management practices can also help but the potential emissions reductions appear to be limited (IPCC 2019).

${ }^{73}$ IEA (2018).
} 
mitigation policies for agriculture have largely focused on subsidies, for example, for more sustainable production methods.

A proxy for agricultural emissions could be priced though, due to import competition, this may do little to promote consumer responses, could cause significant emissions leakage, and may face political resistance. Direct monitoring of farm level emissions is not currently practical. Emissions can however be estimated indirectly using: (i) data on livestock herds, feed, crop production, fertilizer use, and acreage devoted to different practices; (ii) default emissions factors $;{ }^{74}$ and (iii) conventions for converting methane and nitrous oxide emissions into $\mathrm{CO}_{2}$ equivalent. Emissions fees would promote, at the farm level, shifting from livestock to poultry and plant-based production. However, due to potential import competition, these fees may be largely passed back to farmers in lower profits rather than passed forward in higher consumer prices, implying little reinforcement at the consumer level through changes in household diets. Furthermore if, due to reduced competitiveness, reductions in domestic farm production are largely replaced by additional imports, much of the emissions reductions may be offset through leakage.

Feebates related to $\mathrm{CO}_{2}$ equivalent emissions per acre, reinforced by fiscal incentives at the consumer level, may be a more effective approach. Under a feebate, farmers would be subject to an annual fee given by

$$
\begin{gathered}
\left\{\mathrm{CO}_{2} \text { price }\right\} \\
\times\left\{\mathrm{CO}_{2} \text { equivalent/acre }- \text { industrywide average } \mathrm{CO}_{2} \text { equivalent/acre }\right\} \\
\times\{\text { acres under production }\}
\end{gathered}
$$

This scheme would cost-effectively promote all behavioral responses for reducing emissions per acre but with no first-order tax burden on the average farmer. From an administrative perspective, the fees and rebates could be integrated into collection procedures for business tax regimes for farmers, using data on emission rates and acreage compiled by the Ministry of Agriculture and Forestry. Demand responses at the household level might be promoted through taxes on meat and dairy products although there may be some lessons to be learned by the mixed success of previous experiences with 'sin' taxes. ${ }^{75}$

\footnotetext{
${ }^{74}$ IPCC (2019).

${ }^{75}$ For example, Denmark introduced the world's first 'fat' tax in 2011-butter, milk, cheese, pizza, meat, oil and processed food were subject to tax if they contained more than 2.3 percent saturated fat. The tax however was eliminated after only 15 months as businesses were not prepared for reducing fat content and consumers switched to low quality food and cross-border shopping. To enhance effectiveness and acceptability, a meat and dairy tax might be introduced gradually and accompanied by subsidies for plant-based alternatives and an extensive communications program informing the public of the health and environmental benefits of plantbased diets. See Batini and Fontana (2020).
} 
We provide for illustration the effects of feebates with a price of $€ 20$ per tonne of $\mathrm{CO}_{2}$ equivalent in Figure 18. Under the current structure of agricultural production in Finland, a feebate would provide subsidies for plant-based and poultry farming of $€ 14$ and $€ 10$ per acre respectively (18 and 6 percent of farm income respectively), while pig, cattle and dairy farming would pay fees of $€ 11, € 14$ and $€ 29$ per acre $(7,14$, and 18 percent of farm income respectively)—see Table 6.
Figure 18. Illustrative Impact of a Feebate on Agriculture

(Tax/Subsidy, € Per Acre)

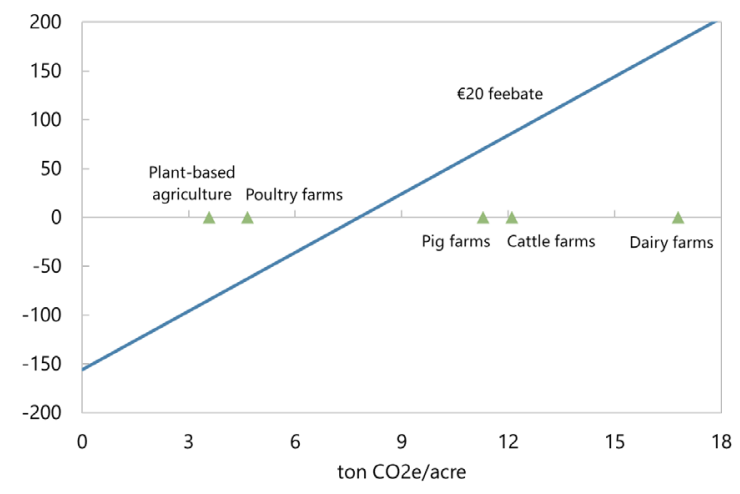

Sources: Danish Council on Climate Change; Statistics Finland; Eurostat; and IMF staff calculations.

Table 6. Impact of a $€ 20$ Per Tonne of $\mathrm{CO}_{2}$ Equivalent Feebate on Agriculture

\begin{tabular}{lcc}
\hline \multirow{2}{*}{ Farm type } & \multicolumn{2}{c}{ Feebate } \\
\cline { 2 - 3 } & $€$ per acre & Percent of farm income \\
\hline Plant-based agriculture & -14 & -18 \\
Poultry farms & -10 & -6 \\
Pig farms & 11 & 7 \\
Cattle farms & 14 & 14 \\
Dairy farms & 29 & 18 \\
\hline Note: Negative values denote a subsidy, positive values a fee.
\end{tabular}

\section{Conclusion}

Using multiple, complementary mitigation instruments to reduce net GHGs in Finland is appropriate, given uncertainties over the effects and feasibility of individual instruments - and fiscal policies have a potentially important role. Strengthening carbon pricing, through higher and more harmonized pricing across sectors, would be the most effective and cost-effective way to make headway on Finland's emissions neutrality goal. Supporting measures at the sectoral level are also needed however, given uncertainties about the emissions impacts and acceptability of higher carbon prices. This paper discusses a variety of fiscal policy options that could complement existing regulatory, infrastructure, and technology policies.

The mitigation strategy Finland develops could be a good prototype for others to follow. Finland aims to be one of the first countries to become emissions neutral- 15 years ahead of most other countries that have pledged emissions neutrality targets. Lessons learned from Finland's experience may inform and improve mitigation strategies in many of these other countries. 


\section{REFERENCES}

ACEA, 2018. ACEA Tax Guide 2018. European Automobile Manufacturers Association. Available at: www.acea.be/uploads/news_documents/ACEA_Tax_Guide_2018.pdf.

Arregui, Nicolas, Christian Ebeke, Jan-Martin Frie, Daniel Garcia-Macia, Dora Iakova, Andy Jobst, Louise Rabier, James Roaf, Chen Ruo, Anna Shabunina, and Sebastian Weber. Forthcoming. "EU Climate Change Mitigation: Sectoral Policies". EUR Departmental Paper, IMF.

Batini, N, 2019. "Macroeconomic Gains from Reforming the Agri-Food Sector: The Case of France". International Monetary Fund WP No. 19/41. Available at: https://www.imf.org/en/Publications/WP/Issues/2019/02/26/Macroeconomic-Gainsfrom-Reforming-the-Agri-Food-Sector-The-Case-of-France-46583

Batini, Nicoletta and Philippe Pointereau, forthcoming 2021. "Greening Food Supply in Advanced Economies" in The Economics of Sustainable Food: Smart Policies for Health and the Planet, Batini, Nicoletta (ed.). Island Press and International Monetary Fund.

Bloomberg, 2020. The European Carbon Market Rally is far from Over.

Böhringer, Christoph, Edward J. Balistreri, and Thomas F. Rutherford. "The role of border carbon adjustment in unilateral climate policy: Overview of an Energy Modeling Forum study (EMF 29)." Energy Economics 34 (2012): S97-S110.

Branger, Frédéric, and Philippe Quirion. "Climate policy and the 'carbon haven' effect." Wiley Interdisciplinary Reviews: Climate Change 5, no. 1 (2014): 53-71.

Bunch, David S., David L. Greene, Timothy Lipman, Dr. Elliot Martin and Dr. Susan Shaheen, 2011, Potential Design, Implementation, and Benefits of a Feebate Program for New Passenger Vehicles in California, pp. 59-61, prepared for the State of California Air Resources Board and the California Environmental Protection Agency.

Burke J., R. Byrnes, and S. Fankhauser. 2019. "How to Price Carbon to Reach Net-Zero Emissions in the UK." Policy Report, London School of Economics, London.

Calder, Jack, 2015, “Administration of a U.S. Carbon Tax,” In Implementing a U.S. Carbon Tax: Challenges and Debates, edited by I. Parry, A. Morris, and R. Williams (New York: Routledge).

CAT, 2020. 2100 Warming Projections. Climate Action Tracker. Available at: https://climateactiontracker.org/global/temperatures.

Clements, Benedict, and David Coady, Stefania Fabrizio, Sanjeev Gupta, Trevor Alleyne, and Carlos Sdralevich, editors, 2013, Energy Subsidy Reform: Lessons and Implications (Washington: International Monetary Fund).

Coady, David. 2006. "Indirect tax and public pricing reforms," in Analyzing the distributional impact of reforms: A practitioner's guide to pension, health, labor markets, public sector downsizing, taxation, decentralization, and macroeconomic modeling (Vol. 2), edited by Aline Coudouel and Stefano Paternostro, World Bank Group, Washington, D.C. 
Danish Agriculture and Food Council, 2019. Annual Statistics for Pigmeat, Beef and Dairy.

Danish Council on Climate Change, 2016. Effective Ways to Reduce Greenhouse Gas Emissions in Agriculture.

Diamond, Peter A., and James A. Mirrlees, 1971. "Optimal Taxation and Public Production I: Production Efficiency.” American Economic Review 61: 8-27.

EC, 2019. Evaluation of the Council Directive 2003/96/EC of 27 October 2003 Restructuring the Community Framework for the Taxation of Energy Products and Electricity. European Commission, Brussels, Belgium.

EU Fusions Project, 2016 (project contributors: Stenmarck, Asa, Carl Jensen, Tom Quested, Graham Moates). Estimates of European food waste levels. Available at:

https://www.eu-

fusions.org/phocadownload/Publications/D3.5\%20recommendations $\% 20$ and $\% 20$ guid elines $\% 20$ food $\% 20$ waste $\% 20$ policy $\% 20$ FINAL.pdf.

Fischer, Carolyn, Richard Morgenstern and Nathan Richardson, 2015, "Carbon Taxes and Energy-Intensive Trade-Exposed Industries: Impacts and Options," In Implementing a U.S. Carbon Tax: Challenges and Debates, edited by I. Parry, A. Morris, and R. Williams. New York: Routledge.

Flachsland, Christian, Michael Pahle, Dallas Burtraw, Ottmar Edenhofer, Milan Elkerbout, Carolyn Fischer, Oliver Tietjen, and Lars Zetterberg, 2018. "Five Myths About a European Union Emissions Trading System Carbon Price Floor." Resources for the Future, Washington, DC.

Gillingham, Kenneth, David Rapson, and Gernot Wagner, 2015. "The Rebound Effect and Energy Efficiency Policy." Review of Environmental Economics and Policy 10: 6888.

Goulder, Lawrence H., Dallas Burtraw and Roberton C. Williams, 1999. "The CostEffectiveness of Alternative Instruments for Environmental Protection in a SecondBest Setting." Journal of Public Economics, Vol. 72, pp. 329-360.

Government of the Netherlands, 2019. Climate Agreement. The Hague. Available at: www.government.nl/documents/reports/2019/06/28/climate-agreement.

Graff Zivin, Joshua, and Matthew Neidell, 2012. "The Impact of Pollution on Worker Productivity." American Economic Review, 102(7), 3652-73.

Heathcote, Jonathan, Kjetil Storesletten, and Giovanni L. Violante, 2017. "Optimal tax progressivity: An analytical framework." The Quarterly Journal of Economics, 132(4), 1693-1754.

Hirst, D., 2018. Carbon Price Floor (CPF) and Price Support Mechanism, Briefing paper 05927, House of Commons Library.

ICAP, 2020. Korea Emissions Trading System. International Carbon Action Partnership.

IEA, 2020. Global Energy Review 2020: The Impacts of the Covid-19 Crisis on Global Energy Demand and CO2 Emissions. International Energy Agency, Paris, France. 
IEA, 2019. Energy Prices and Taxes, First Quarter. International Energy Agency, Paris, France.

IEA, 2018. Energy Policies of IEA Countries: Finland 2018. International Energy Agency, Paris, France.

IMF, 2019. Fiscal Policies for Paris Climate Strategies-From Principle to Practice. Washington, DC.

IMF, 2020. The Time is Right! Reforming Fuel Pricing Under Low Oil Prices. Available at: https://www.imf.org/en/Publications/SPROLLs/covid19-special-notes.

IPCC, 2018. Global Warming of $1.5^{\circ}$ C. Inter-Governmental Panel on Climate Change, Available at: https://www.ipcc.ch/sr15.

2019. Climate Change and Land: An IPCC Special Report on Climate Change, Desertification, Land Degradation, Sustainable Land Management, Food Security, and Greenhouse Gas Fluxes in Terrestrial Ecosystems. Geneva. Available at: https://www.ipcc.ch/srccl-report-download-page/

Jochem, Patrick, Claus Doll, and Wolf Fichtner, 2016. "External Costs of Electric Vehicles." Transportation Research Part D: Transport and Environment 42: 60-76.

Luxembourg Income Study (LIS) Database, http://www.lisdatacenter.org (Finland; last accessed in March 2021). Luxembourg: LIS.

McKinsey, 2018. Charging ahead: Electric-vehicle infrastructure demand. Available at: www.mckinsey.com/industries/automotive-and-assembly/our-insights/chargingahead-electric-vehicle-infrastructure-demand.

Misch, Florian and Philippe Wingender, 2021. "Emission Spillovers from Carbon Price Increases: New Evidence and Policy Questions." Working Paper, International Monetary Fund, Washington DC.

MOE, 2020. Annual Climate Report 2020. Ministry of the Environment, Helsinki, Finland.

MOF, 2021. Report of the working group on energy taxation reform: A proposal for implementing the intentions and goals of the Government Programme and for further development of energy taxation. Ministry of Finance, Helsinki, Finland.

Ministry of Transport Building and Housing, 2020. Report of the Working Group on Fossil Free Transport. Forthcoming.

Ministry of Transport Building and Housing, 2017. National policy framework for implementation of the AFI Directive.

NCEP, 2019. Denmark's Integrated National Energy and Climate Plan. Danish Ministry of Climate, Energy, and Utilities.

OECD, 2019. Taxing Energy Use 2019: Using Taxes for Climate Action, OECD Publishing, Paris. 
Parry, Ian W.H., 2019. “The Rationale for, and Design of, Forest Carbon Feebates.” In Designing Fiscal Instruments for Sustainable Forests, World Bank Group, Washington DC, 2020, 137-158.

Parry, Ian, 2004. “Are Emissions Permits Regressive?” Journal of Environmental Economics and Management 47: 364-387.

Parry, Ian, Chandara Veung and Dirk Heine, 2015. "How Much Carbon Pricing is in Countries Own Interests? The Critical Role of Co-Benefits." Climate Change Economics 6, 1550019-1-26.

Parry, Ian and Roberton Williams, 2012. "Moving US Climate Policy Forward: Are Carbon Tax Shifts the Only Good Alternative?" In Robert Hahn and Alistair Ulph (eds.), Climate Change and Common Sense: Essays in Honor of Tom Schelling, Oxford University Press, 173-202.

Parry, Ian, Dirk Heine, Shanjun Li, and Eliza Lis, 2014. Getting Energy Prices Right: From Principle to Practice. IMF, Washington DC.

Sedjo, R., and G. Marland, 2003, "Inter-Trading Permanent Emissions Credits and Rented Temporary Carbon Emissions Offsets: Some Issues and Alternatives." Climate Policy 3: 435-444.

Sijm, J. and others, 2012. "The impact of power market structure on the pass-through of CO2 emissions trading costs to electricity prices - A theoretical approach". Energy Economics, Elsevier, 34: 1143-1152.

Tsyvinski, A., and Werquin, N. 2019. “Generalized Compensation Principle,” Toulouse School of Economics Working Paper No. 19-1051.

Vallgårda, S., Holm, L. and Jensen, J., 2015. "The Danish tax on saturated fat: Why it did not survive," European Journal of Clinical Nutrition, 69, 223-226.

Verdolini, E., Vona, F., and D. Popp, 2018. "Bridging the Gap: Do Fast Reacting Fossil Technologies Facilitate Renewable Energy Diffusion?” Energy Policy 116: 242-256.

VTT, 2018. Growth by integrating bioeconomy and low-carbon economy Scenarios for Finland until 2050.

Walter Willett, Johan Rockström, Brent Loken, Marco Springmann, et al., 2019, "Food in the Anthropocene: the EAT-Lancet Commission on healthy diets from sustainable food systems," EAT-Lancet EAT-Lancet Commission on healthy diets from sustainable food systems.

World Bank, 2020. "State and Trends of Carbon Pricing 2020” (May), World Bank, Washington, DC. 


\section{APPENDiX I. BuRden OF CARbon Mitigation Policies On INDUSTRIES}

\section{Conceptual Analysis}

The burden - or increase in private production costs - for industries from carbon mitigation policies is depicted graphically in Figure A1. Here the upper, middle, and lower curves are respectively the marginal cost of reducing emissions through reducing domestic industry output, reducing the emissions intensity of output and the envelope of these two curves. A carbon pricing policy reduces emissions by $\Delta \mathrm{E}^{\text {tot }}$, with $\Delta \mathrm{E}^{\text {int }}$ and $\Delta \mathrm{E}^{\text {out }}$ coming from reduced emissions intensity and reduced output respectively.

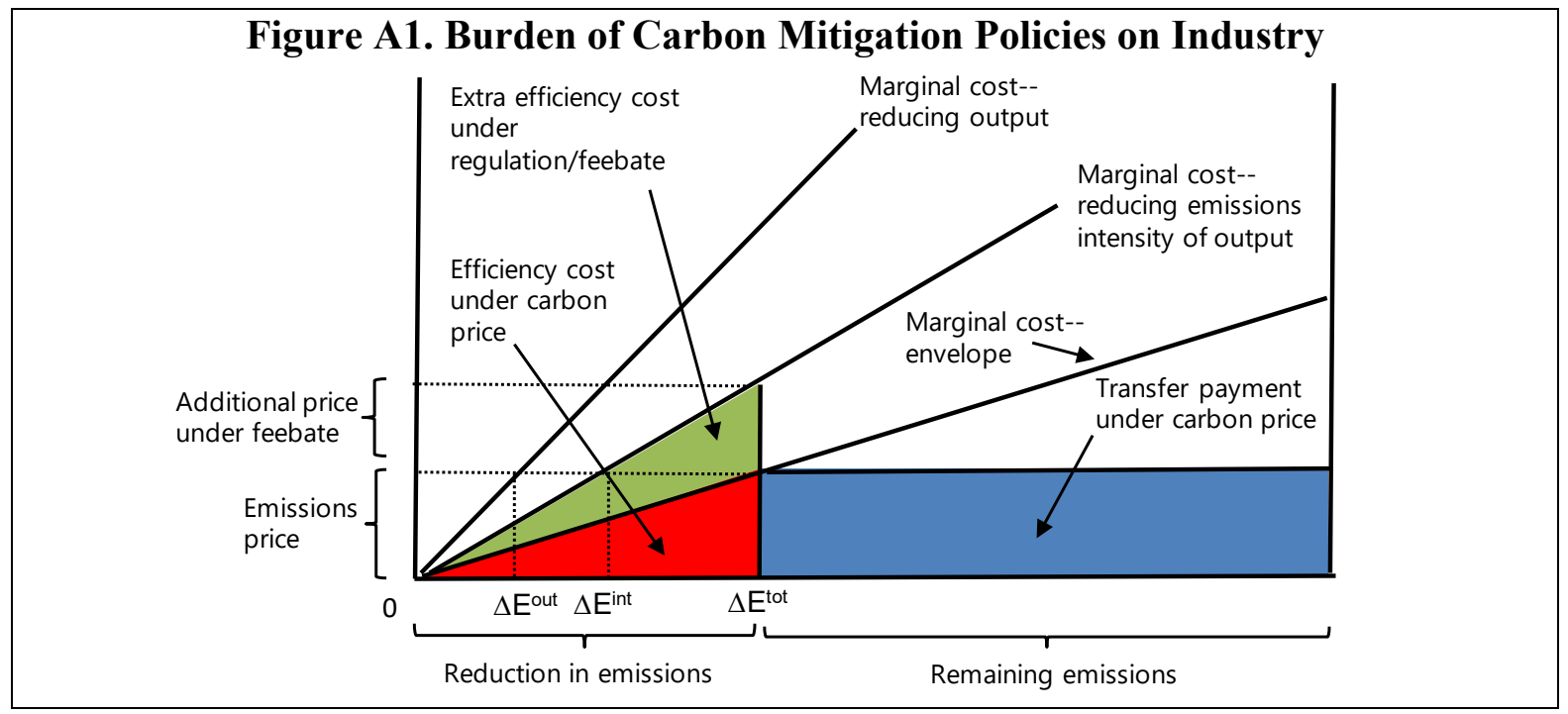

The burden of carbon pricing on industries has two components. One is the second-order efficiency cost of the behavioral responses (the red triangle in the Figure) reflecting the resource cost of adopting cleaner (but costlier) production methods. The other is the firstorder transfer payment, for example, payments to the government for emission allowances to cover remaining emissions (the blue rectangle). Free allowance allocation would offset the transfer payment component of the burden, though this mechanism becomes less effective for compensating EITE industries at deeper levels of decarbonization because the efficiency cost increases in size relative to the transfer payment.

Alternative mitigation instruments to carbon pricing are less efficient but may impose a much smaller burden on industries. A feebate applied to an industry reduces emissions intensity but (to an approximation) has no impact on output as, unlike a carbon price, it does not charge for remaining emissions. The burden of the feebate-assuming the industry emissions reduction is the same as under the carbon price - includes a higher efficiency cost (the extra green triangle in the Figure) but there is no transfer payment. The efficiency cost of the feebate (again from simple geometry) is equivalent to that under carbon pricing (the red triangle) times $\Delta \mathrm{E}^{\text {tot }} / \Delta \mathrm{E}^{\mathrm{int}}$. But the overall burden is generally lower under the feebate, especially for relatively low abatement levels, as there is no transfer payment under these policies. For example, if $\Delta \mathrm{E}^{\mathrm{tot}} / \Delta \mathrm{E}^{\text {int }}=1.5$ (i.e., two-thirds of the emissions reduction under the carbon price comes from reduced emissions intensity) the burden of the feebate is 21,50 , and 90 percent of that under carbon pricing for emissions reductions of 25,50 , and 75 percent respectively. 


\section{Illustrative Impacts of Carbon Pricing and Feebates on Production Costs for Steel and Cement}

Steel. Traditionally steel is produced using an integrated process involving heating coal to form coke, feeding coke and iron ore into a blast furnace, and using an oxygen furnace to purify the molten metal - the process produces about two tons of $\mathrm{CO}_{2}$ per ton of steel. ${ }^{1}$ Alternatives include an electrified process using scrap metal, and emerging technologiesfor example, applying CCUS, or feeding an electric furnace with iron made by direct reduction (e.g., using natural gas). These alternatives produce $\mathrm{CO}_{2}$ emissions of about $0.3-$ 0.4 tons per ton of steel.

A carbon price of $€ 50 /$ ton of $\mathrm{CO}_{2}$ would increase the cost of integrated production by about $€ 100 /$ ton of steel through the first-order transfer payment, about one sixth of recent steel prices. $^{2}$ And it would increase the cost under alternative technologies by about $€ 20 /$ ton of steel. ${ }^{3}$ In contrast, under a feebate the cost for integrated production (given an assumed industry average emission rate of 1 ton of $\mathrm{CO}_{2}$ per ton of steel) would increase $€ 50$ per ton of output, while alternative technologies would receive a subsidy of about $€ \$ 30$ per ton of output. A higher

Cement. About 90 percent of cement is produced using traditional kilns to decompose calcium carbonate into clinker and $\mathrm{CO}_{2}$ and then using mills to mix clinker with other minerals like limestone and grinding it - the process produces about 1 ton of $\mathrm{CO}_{2}$ per one ton of cement, with process emissions contributing about 70 percent of these emissions. Alternatives include state-of-the-art plants in terms of energy efficiency, currently about 10 percent of production, and CCUS - either post-combustion (where $\mathrm{CO}_{2}$ is extracted from exhaust gases) or oxy-combustion (where fuel is burned with a mixture of pure oxygen and exhaust gases). State-of-the-art plants largely eliminate non-process emissions. Post- and oxy-combustion reduce emissions about 55 and 85 percent respectively, while increasing capital costs by about 25 and 100 percent respectively.

A carbon price of $€ 50 /$ ton of $\mathrm{CO}_{2}$ would increase the cost of traditional production about $€ 50$ per ton of cement, or about 40 percent, ${ }^{4}$ while increasing the price of more efficient and CCUS-fitted plants by $€ 30$, and $€ 8-25$ per ton of output respectively through the first-order transfer payment. In contrast, a feebate with price $\$ 50 /$ ton of $\mathrm{CO}_{2}$ would only increase the cost of traditional production by $€ 5$ per ton of cement, while providing a subsidy to more efficient and CCUS-fitted plants of $€ 10$ and $€ 18-35$ per ton of output.

\footnotetext{
${ }^{1}$ Unless otherwise noted, all data in this box is taken from van Reijven and others (2016).

${ }^{2}$ See www.focus-economics.com/commodities/base-metals/steel-europe.

${ }^{3}$ Technology switching is more likely to take the reform of retrofitting existing plants, rather than scrapping plants and building new ones, given that existing steel factories can potentially produce for several decades. Incentives will vary across plants, for example with local fuel and electricity prices.

${ }^{4}$ From www.marketresearch.com/Global-Research-Data-Services-v3891/Cement-Finland-Size-DevelopmentForecasts-9083849/).
} 


\section{APPENDIX II. HouSEHOLd INCIDENCE OF A CARBON TAX}

The incidence of carbon tax changes depends on changes in: i) energy prices, ii) prices for other goods and services, and iii) wages. The derivation for consumer price changes below follows the approach proposed by Coady (2006).

\section{A. Production and Pass Through to Non-Energy Goods}

Assume profits of a representative firm are given by

$$
\Pi_{j}=p_{j} f\left(A_{j}, E_{j}, L_{j}\right)-q A_{j}-r E_{j}-w_{j} L_{j}
$$

with $p_{j}$ the supplier price of good $j, q$ a $1 \times n$ row vector of user prices for intermediate inputs and $A_{j}$ a $n \times 1$ column vector of quantities, $r$ and $E_{j}$ the price and quantity of energy, and with labor costs $w_{j} L_{j}$. The element $A_{i j}$ denotes the quantify of input $i$ needed to produce output $y_{j}$. We assume Leontief production $Y_{j}=f\left(A_{j}, E_{j}, L_{j}\right)$ so that input shares are fixed. Producer and user prices are related by $q=p+t$, with $t$ general sales and excise taxes, tariffs, and subsidies.

A carbon tax $\tau$ directly affects the user price of energy $r$ and indirectly the prices of other domestic inputs $q$

$$
\frac{\partial \pi_{j}}{\partial \tau}=\frac{\partial p_{j}}{\partial \tau}-\frac{\partial q}{\partial \tau} a_{j}-\frac{\partial r}{\partial \tau} e_{j}-\frac{\partial w_{j}}{\partial \tau} l_{j}
$$

with $x_{j}=X_{j} Y_{j}^{-1}$. For domestic suppliers, we further assume that:

- Higher input costs are fully passed on through higher producer prices $p_{j}^{d}$

- Profits are constant through a no-arbitrage condition

- User prices of imported goods are not affected.

This implies

$$
\frac{\partial p_{j}^{d}}{\partial \tau}=\frac{\partial q^{d}}{\partial \tau} \alpha a_{j}+\frac{\partial r}{\partial \tau} e_{j}
$$

with $\alpha$ a diagonal matrix that denotes the share of goods that are produced domestically. When other taxes remain constant, changes in producer prices of non-energy goods are equal to changes in user prices. Re-expressing price changes in Eq. (3) in percentage terms and concatenating across goods yields

$$
\frac{\partial \dot{p}^{d}}{\partial \tau}=\frac{\partial \dot{q}^{d}}{\partial \tau}=\frac{\partial \dot{q}^{d}}{\partial \tau} \alpha \Lambda+\frac{\partial \dot{r}}{\partial \tau} \Sigma
$$


with $\partial \dot{x} \equiv \partial x / x$ the percentage price changes, the matrix $\Lambda$ an input-output coefficient matrix of size $n \times n$ and $1 \times n$ row vector of energy intensity $\Sigma=\left[\frac{r E_{1}}{p_{1}^{d} Y_{1}}, \frac{r E_{2}}{p_{2}^{d} Y_{2}}, \ldots, \frac{r E_{n}}{p_{n}^{d} Y_{n}}\right] \cdot{ }^{1}$

Rearranging, we can solve for changes in user prices

$$
\frac{\partial \dot{q}^{d}}{\partial \tau}=\frac{\partial \dot{r}}{\partial \tau} \Sigma K
$$

with Leontief inverse matrix $K=(I-\alpha \Lambda)^{-1}$.

In the case of exporters, we further assume

- Perfect substitutability with foreign goods so that higher input costs are instead passed back to wages

- No labor reallocation between exporters and domestic suppliers.

From Eq. (2),

$$
\frac{\partial w_{j}^{*}}{\partial \tau} l_{j}=-\frac{\partial q^{d}}{\partial \tau} \alpha a_{j}-\frac{\partial r}{\partial \tau} e_{j}
$$

which can be re-expressed as

$$
\frac{\partial \dot{w}_{j}^{*}}{\partial \tau}=-\frac{\partial \dot{r}}{\partial \tau} \Sigma(I+K \alpha \Lambda) \lambda^{-1}
$$

where the elements of the diagonal matrix $\lambda$ are equal to the labor intensity of production $w_{j} L_{j} / p_{j}^{d} Y_{j}$.

\section{B. Household Incidence}

We assume quasi-linear utility over total consumption $C_{i}$ and labor supply $L_{i}$

$$
U_{i}\left(C_{i}, L_{i}\right)=C_{i}-\frac{1}{1+1 / e} L_{i}^{1+1 / e},
$$

with $e$ the elasticity of labor supply. We incorporate household heterogeneity by assuming consumption $C_{i}$ in Eq. (5) is a CES bundle of $j$ goods with elasticity of substitution $\sigma$ and skills-specific expenditure shares $\omega_{j}^{i}$

\footnotetext{
${ }^{1}$ A standard input-output matrix would also include energy inputs. The notation used here effectively precludes second-round effects on energy price themselves. Both approaches are equivalent however when the carbon policy targets the total energy price change.
} 


$$
C_{i}=\left(\sum_{j} \omega_{j}^{i} c_{i}^{\frac{\sigma-1}{\sigma}}\right)^{\frac{\sigma}{\sigma-1}}
$$

Individual $i$ chooses the specific bundle of size $C_{i}$ that minimizes her expenditures $E_{i}=$ $\sum_{j} p_{j} c_{j}$. This allows us to write the consumer's budget constraint as

$$
P_{i} C_{i}=w_{i} L_{i}-T\left(w_{i} L_{i}\right)
$$

with $P_{i}=\left[\sum_{j}\left(\omega_{j}^{i}\right)^{\sigma}\left(p_{j}\right)^{1-\sigma}\right]^{\frac{1}{1-\sigma}}$ the ideal price index for the consumption bundle of individuals with skills $i, w_{i} L_{i}$ labor earnings and tax liabilities $T\left(w_{i} L_{i}\right)$ A progressive (regressive) tax schedule features a positive first derivative-which corresponds to the marginal tax rate - that is increasing (decreasing) in the level of earnings.

Maximization of Eq. (5) subject to the budget constraint gives the following solution for the labor supply of workers with skills $i$

$$
L_{i}^{*}=\left[\frac{w_{i}}{P_{i}}\left(1-T^{\prime}\left(w_{i} L_{i}^{*}\right)\right)\right]^{e} .
$$

This condition states that a one percent increase in wages $w_{i}$, a one percent decrease in the overall price level of the consumption bundle $P_{i}$ and a one percent increase in the net-of-tax rate $1-T^{\prime}\left(w_{i} L_{i}^{*}\right)$ all have the same impact of $e$ on labor supply since

$$
d \log L_{i}^{*}=e d \log \left(w_{i}\right)-e d \log \left(P_{i}\right)+e d \log \left(1-T^{\prime}\left(w_{i} L_{i}^{*}\right)\right) .
$$

The welfare effects of a carbon tax change can be approximated using Eq. (5), by replacing $C_{i}$ with $L_{i}^{*}$ from Eq. (8) using the individual budget constraint from Eq. (7) and taking the derivate with respect to $\tau$. Moreover, with quasi-linear utility, changes in the consumer surplus $d U_{i}^{*}$ are equivalent to changes in income. We can therefore express welfare changes as a share of pre-tax real earnings $\frac{w_{i}}{P_{i}} L_{i}^{*}$. After some manipulation, this can be expressed as

$$
\frac{d U_{i}^{*} / d \tau}{\frac{w_{i}}{P_{i}} L_{i}^{*}}=\left(1-T^{\prime}\left(w_{i} L_{i}^{*}\right)\right) \frac{d w_{i}}{w_{i}}-\left(1-\frac{T\left(w_{i} L_{i}^{*}\right)}{w_{i} L_{i}^{*}}\right) \frac{d P_{i}}{P_{i}}
$$

where we used the envelope condition for labor supply. The first term on the right hand-side shows that individuals' utility losses are less than the full decline in wages since the lower (nominal) earnings also reduce tax liabilities (by one minus the marginal tax rate). The second term shows individuals' utility losses are less than the full increase in consumer prices since consumption expenditures are done after income taxes are paid. The adjustment in this case is one minus the average tax rate.

Finally, using the demand for individual goods $c_{i}$ from the expenditure minimization nest 


$$
c_{j}=\left(\omega_{j}^{i}\right)^{\sigma}\left(\frac{p_{j}}{P_{i}}\right)^{-\sigma} \frac{E_{i}}{P_{i}}
$$

we can calculate the incidence on individual with skill level $i$ of a carbon tax change as

$$
(1-m t r) d \dot{w}_{i}-(1-a t r) \sum_{j} \omega_{j}^{i} d \dot{p}_{j}
$$

Eq. (10) states that the impact of a carbon tax on individuals' welfare is the sum of two terms: i) the percentage change in wages multiplied by one minus the marginal tax rate; and ii) the percentage changes in consumer prices, weighted by their final consumption budget shares $\omega_{j}^{i}$, multiplied by one minus the average tax rate.

For the empirical implementation, we use energy price changes resulting from a carbon tax from the model developed by Parry and others (2014). The price changes of other domestic supplies are calculated from an input-output table for Finland using Eq. (2) and matched to consumption tables by income quintiles from Eurostat. Wage changes for exporters by sector are calculated from Eq. (3) and matched to household survey data to calculate changes in wages throughout the income distribution. As mentioned above, we assume only the price of energy and domestically produced non-energy goods are affected by the carbon tax, while only wages paid by exporters are reduced.

For the marginal and average tax rates used in Eq. (10), we estimate the parameters of constant rate of progressivity (CRP) tax schedule for Finland using actual income and taxes paid from the household survey data. The data are from the 2017 Income Distribution Survey accessed via the LIS platform. A CRP tax schedule is described by

$$
T\left(w_{i} L_{i}\right)=w_{i} L_{i}-\frac{1-\alpha}{1-\gamma}\left(w_{i} L_{i}\right)^{1-\gamma},
$$

for some parameters $\gamma \in(-\infty, 1)$ and $\alpha \in \mathbb{R}$ (see Heathcote, Storesletten, and Violante, 2017). The values of $\gamma$ and $\alpha$ estimated from the microdata on earnings and direct taxes paid are 0.106 (standard error 0.002) and -0.965 (standard error 0.041), respectively. This functional form provides a good description overall of the tax schedule with a regression R-squared of 0.95 .

Finally, the changes in labor supply reported in the main text are obtained using Eq. (9). The compensating tax reform is calculated using Proposition 2 in Tsyvinski and Werquin (2019) by replacing the exogenous wage change with $\left(d \dot{w}_{i}-\frac{1}{1-\gamma} \sum_{j} \omega_{j}^{i} d \dot{p}_{j}\right)$. 


\section{APPENDIX III. DESIGN ISSUES FOR A BCA: FURTHER DISCUSSION}

- Industry coverage. It would be preferable initially to target EITE industries, since they account for the largest share of trade-embedded carbon, face the highest carbon leakage rates, and their embodied carbon is more reliably estimated than for products with low embodied carbon - embodied carbon in EITE imports was 14 million tons in 2015 , or 30 percent of the size of domestic CO2 emissions. This narrow BCA would also strengthen the environmental justification of the measure (which could also become important when assessing consistency with trade law rules as discussed below). Administrative costs would also be minimized early on as systems and procedures are developed and scaled over time. Consideration should be given to eventually cover all sectors, both other non-energy intensive industry and services which account for 55 percent of embodied carbon in all imports to Finland. Whether this extension is worthwhile would depend on whether any additional emissions benefits outweigh the extra administrative burden.

- Country benchmark for embodied carbon. The carbon content of traded goods is not readily observable. A possible solution could involve the use of trading partners' industry-specific averages, based on internationally recognized methodologies for measuring carbon intensity in industries at the country level. While crude, the use of macro-measures of carbon content would still serve an important purpose as they could incentivize trading partners to adopt carbon pricing themselves, at least for BCAs in large jurisdictions such as the EU.

- Rebates for domestic exporters. Providing rebates for embodied carbon pricing in exports leaving Finland would help to address the adverse competitiveness impacts for domestic exporters. At the same time, it also reduces incentives for these producers to reduce their emissions - implying a greater burden of reduction for other domestic emissions sources if a domestic mitigation pledge is to be met-rebating also lowers revenues from domestic carbon pricing. A sequenced implementation might therefore be advisable, with the BCA applying initially only to imports. This would also have the advantage of better managing the underlying legal sensitivities associated with granting export rebates/subsidies under trade law rule. ${ }^{1}$ In 2015, around 35 percent of domestic carbon emissions in Finland where embodied in exports.

- $\quad$ Revenue use. Revenues from a BCA might be used to lower the likelihood of legal challenges to the BCA. Some of the proceeds could be given back to governments of exporting, developing countries or to finance green development abroad, for instance by channeling the revenues to the Green Climate Fund. Such a transfer mechanism could also be consistent with existing international climate finance obligations (for example, under the Paris Agreement). Nonetheless, most of the burden of a BCA in a

\footnotetext{
${ }^{1}$ This phased approach is also being considered as an option in the context of incorporating BCAs into the EU ETS.
} 
small open economy like Finland would likely be borne by domestic consumers rather than trading partners.

- $\quad$ Adjusting import charges for carbon pricing overseas. In principle, a BCA should ensure equal tax treatment for units of carbon emitted domestically and tradeembedded units that were emitted abroad. A credit should then be given for the tax already paid abroad on the embedded carbon. If the primary motivation for the BCA is addressing competitiveness/leakage concerns, the BCA might be linked to pricing just for the power generation and industrial sectors in overseas countries - transparent data on pricing schemes for these sectors is readily available. Ultimately there could be a transition to measures of 'effective' carbon pricing that account for pricing of $\mathrm{CO} 2$ emissions from other sectors and pre-existing taxes (e.g., road fuel excises) on those fuels as measurement conventions are developed.

- $\quad$ Rebating for individual overseas exporters with embodied carbon below their industry average. The use of macro measures of carbon content would not incentivize carbon mitigation for individual foreign producers since the tax would not depend on their own carbon footprint. This could be addressed by adopting a "rebuttable" presumption, meaning importers would be allowed to provide certification from an internationally recognized body if their carbon intensity is lower than the country-sector average. ${ }^{2}$ There is a risk of gaming however, if firms dedicate production from their cleaner plants for export to the BCA area while supplying customers in other countries or at home with production from emissions-intensive plants.

- Differentiating charges by country income. As a general principle, tax law design of BCAs should ideally avoid differentiation of imports by country of origin. However, exceptions could be granted for imports from "least developed countries" (consistent with existing trade law mechanisms). Applying a lower BCA rate for exporters in low-income countries would partially undermine the ability of the BCA to address competitiveness and leakage, but it is more equitable. Administrative complexities might be limited through use of a simple formula: for example, a 100 percent discount on the BCA for low-income developing countries.

\footnotetext{
${ }^{2}$ Examples of such certifications include the World Resource Institute/World Business Council on Sustainable Development GHG Protocol or the ISO 14064 standard.
} 
APPENDIX IV. CARbON TAXES: 2018 vs 2021

Table A1. Carbon Taxes by Major Fuel Type in Finland, $€ /$ tonne

\begin{tabular}{lcc}
\hline \multicolumn{1}{c}{ Sector/fuel type } & $\mathbf{2 0 1 8}$ & $\mathbf{2 0 2 1}$ \\
& & \\
\hline Electricity & 0 & 0 \\
Coal and other solid fuels & & \\
$\begin{array}{l}\text { Industry } \\
\text { Coal and other solid fuels }\end{array}$ & 25 & 36 \\
Natural gas & 74 & 87 \\
Road transport & & \\
Gasoline & 311 & 337 \\
Diesel & 199 & 224 \\
Buildings & & 104 \\
Diesel & 92 & \\
\hline
\end{tabular}

Source: MOF (2021), MOF (updated), OECD (2019) (updated).

Note. Cabon tax is the sum of domestic carbon tax and fuel tax (on energy content). See Table 3. 